\title{
Blends of ethylene-co-vinyl acetate and poly(3-hydroxybutyrate) with adhesion property
}

\author{
A. de Lucas-Freile ${ }^{1}$, S. Sancho-Querol ${ }^{1}$, A. J. Yáñez-Pacios ${ }^{1}$, L. Marín-Perales ${ }^{2}$, \\ J. M. Martín-Martínez ${ }^{1 *}$ \\ ${ }^{1}$ Adhesion and Adhesives Laboratory, Department of Inorganic Chemistry, University of Alicante, 03080 Alicante, Spain \\ ${ }^{2}$ Repsol Technology Centre, 28935 Móstoles (Madrid), Spain
}

Received 11 December 2017; accepted in revised form 1 February 2018

\begin{abstract}
The structure and properties of ethylene-co-vinyl acetate (EVA) and poly(3-hydroxybutyrate) (PHB) blends depended on their PHB content, i.e. PHB phase dominated the structure for amounts of PHB higher than 50 wt $\%$, whereas EVA phase is dominant for PHB content lower than $50 \mathrm{wt} \%$. EVA/PHB (70:30) blend showed unexpected different structure because of higher miscibility and the creation of new interfacial interactions between $\mathrm{C}=\mathrm{O}$ and $\mathrm{CH}_{3}$ groups of $\mathrm{PHB}$ and $\mathrm{CH}_{3}$ and $\mathrm{C}=\mathrm{O}$ groups of EVA, these interactions led changing of the phase structure of ethylene and vinyl acetate domains in EVA. As a consequence, improved thermal, viscoelastic and morphological properties were obtained. EVA+PHB blends containing $60 \mathrm{wt} \%$ or more PHB did not show tack and, interestingly, the addition of $20-30 \mathrm{wt} \%$ PHB enhanced the tack and displaced the maximum tack of pure EVA to lower temperature. The tack of EVA/PHB (70:30) blend was the highest among all blends because of its particular structure, fibrillation was also shown. Finally, the adhesion of EVA+PHB blends containing 20-30 wt \% PHB to polypropylene (PP) substrate was higher than the one of pure EVA because of the interactions between the ethylene domains in EVA phase of the blend and PP substrate surface.
\end{abstract}

Keywords: polymer blends and alloys, adhesion, ethylene-co-vinyl acetate, poly(3-hydroxybutyrate), tack

\section{Introduction}

There is current interest in reducing $\mathrm{CO}_{2}$ emissions by replacing polymers derived from petroleum by more eco-friendly polymers without sacrificing properties. During the last decade, biopolymers obtained from renewable sources have received particular attention [1], the polyhydroxyalkanoates (PHAs) synthesized by bacterial fermentation of different renewable resources are particularly promising [2]. PHAs are bio-polyesters derived from 3-hydroxy fatty acids containing from 3 to 14 carbons with different side chain lengths [3, 4]. Some PHAs are thermoplastic and all then are water insoluble, they have good resistance to ultraviolet (UV) radiation, and they are biocompatible and biodegradable [1]. The most commonly studied and the simplest PHA is poly(3-hydroxybutyrate) (PHB) which is produced by several microorganisms in nature [5]. PHB polymer is currently used in drug delivery, packaging and medical applications.

Because of the high crystallinity, brittleness and stiffness of $\mathrm{PHB}$, it has narrow processing temperature window [6-9]. To solve these drawbacks, the copolymerization by fermentation with another PHA of higher side chain length has been proposed [10, 11]. Alternatively, for improving the processability and the mechanical properties, blends of PHB with several thermoplastic polymers including poly(ethylene oxide), poly(epichlorohydrin), poly(vinyl acetate), poly(vinylidene fluoride), and poly(ethylene-co-vinyl acetate copolymer) (EVA), among others, have been proposed [12-16]. For example, Abbatte et al. [17]

"Corresponding author, e-mail: jm.martin@ua.es

(C) BME-PT 
prepared blends of random ethylene-propylene rubber copolymer with functional ester or anhydride groups, modified EVA and poly(D(-)3-hydroxybutyrate), and they found that a decrease in the particle size of the dispersed phase, an increase in adhesion to the matrix, improved elongation-at-break and toughness. Ma et al. [18] prepared blends of poly(hydroxyalkanoate)s and EVA with vinyl acetate content of $90 \mathrm{wt} \%$ (EVA90) that exhibited high tensile strength, high elongation-at-break $(>800 \%)$, good strain-recovery $(>60 \%)$, and adequate melt processability; furthermore, the spherulite growth rate of poly(hydroxyalkanoate)s decreased by increasing EVA90 content.

Due to environmental concern, there is an interest in developing biodegradable adhesives, mainly in food packaging. Biodegradable adhesives with adequate adhesion properties have not been developed yet. Ethylene-co-vinyl acetate (EVA) copolymer is widely used in the manufacture of non-biodegradable hot melt adhesives in which the combination with tackifiers and waxes is mandatory for obtaining good adhesion property. EVA hot melts are widely used for bonding materials in packaging, textile and furniture industry, and hygiene products, among others. The properties of EVA copolymers, including adhesion, are controlled by their vinyl acetate content and melt flow index. Recently, the potential of pure EVA as adhesive for bonding polyamide to metal has been shown, but the adhesion obtained was poor [19]. On the other hand, the use of PHA as partially biodegradable adhesive has been scarcely considered in the existing literature. Babu et al. [20] proposed the mixture of medium chain length PHAs with tackifiers after being partially crosslinked by UV radiation for rending pressure sensitive adhesives. Whereas PHAs lacked of adhesion properties, the addition of different tackifiers produced pressure sensitive adhesives with good peel and shear strength values but poor cohesion.

Whereas the properties of EVA+PHB blends for reducing stiffness and improving the mechanical properties of PHB have been widely studied, their adhesion properties have not been considered yet. PHB shows no adhesion property and adhesion of EVA is poor. Because of the absence of studies on the adhesion properties of EVA+PHB blends, in this work different blends of PHB and EVA with vinyl acetate content of $40 \mathrm{wt} \%$ were prepared, and their structure and adhesion properties at different temperatures were characterized. The results obtained in this study have shown that some EVA+PHB blends exhibit good adhesion property and, more interesting, these blends show very different and controlled adhesion in a narrow range of temperature.

\section{Experimental}

\subsection{Materials}

Poly(3-hydroxybutyrate) (PHB) pellets - Mirel F3002 - produced by bacterial fermentation were supplied by Metabolix (Lowell, MA, USA). Ethylene-co-vinyl acetate (EVA) copolymer containing $40 \mathrm{wt} \%$ vinyl acetate and having melt flow index (MFI) of $55 \mathrm{~g} / 10 \mathrm{~min}\left(190^{\circ} \mathrm{C} ; 2.16 \mathrm{~kg}\right)$ was supplied by Repsol (Madrid, Spain). For preventing premature ageing, $0.5 \mathrm{wt} \%$ Irganox $1010^{\circledR}$ antioxidant (BASF, Kaisten, Switzerland) was added to EVA+PHB blends. The chemical structure and some characteristics of PHB and EVA are given in Table 1.

\subsection{Preparation of $E V A+P H B$ blends}

$10 \mathrm{~g}$ of different EVA+PHB blends were prepared in an aluminum container at $180^{\circ} \mathrm{C}$ in a Thermosel ${ }^{\mathbb{R}}$ Brookfield system (Harlow, UK); PHB was added

Table 1. Nomenclature, chemical structure and some characteristics of the raw materials.

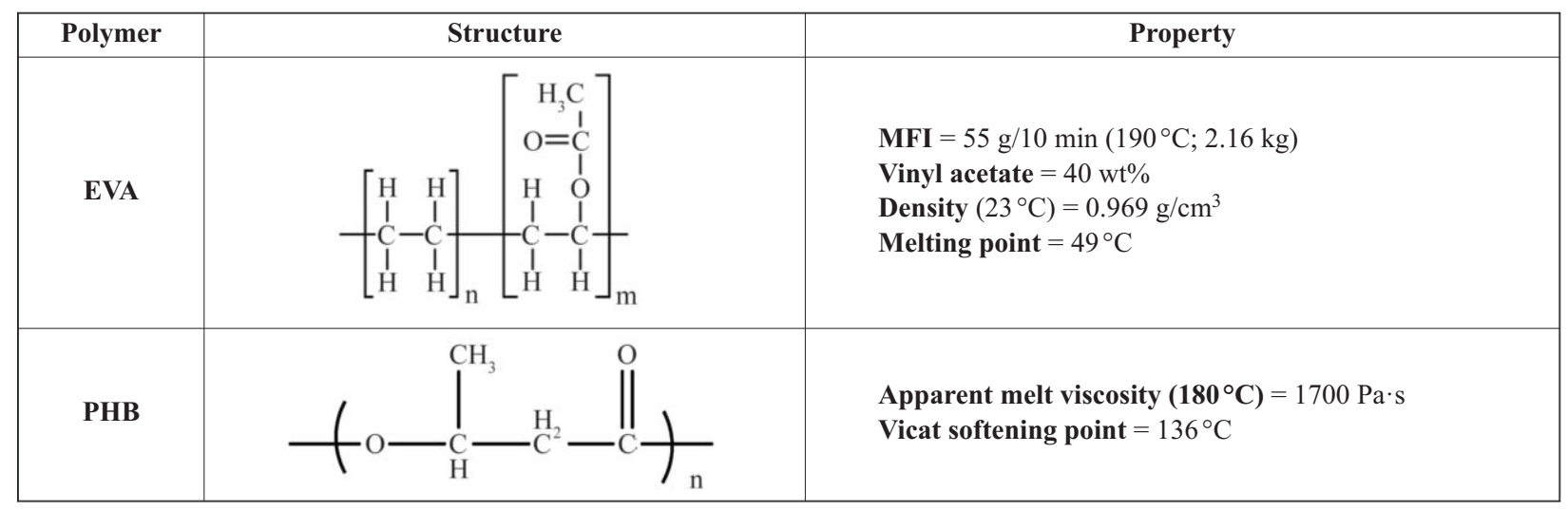


Table 2. Nomenclature and composition of EVA+PHB blends.

\begin{tabular}{|c|c|}
\hline Blend & Composition \\
\hline EVA/PHB (80:20) & $80 \mathrm{wt} \%$ EVA $+20 \mathrm{wt} \%$ PHB \\
\hline EVA/PHB (70:30) & $70 \mathrm{wt} \%$ EVA $+30 \mathrm{wt} \%$ PHB \\
\hline EVA/PHB (60:40) & $60 \mathrm{wt} \%$ EVA $+40 \mathrm{wt} \%$ PHB \\
\hline EVA/PHB (50:50) & $50 \mathrm{wt} \%$ EVA $+50 \mathrm{wt} \%$ PHB \\
\hline EVA/PHB (40:60) & $40 \mathrm{wt} \%$ EVA $+60 \mathrm{wt} \%$ PHB \\
\hline EVA/PHB (30:70) & $30 \mathrm{wt} \%$ EVA $+70 \mathrm{wt} \%$ PHB \\
\hline EVA $/$ PHB (20:80) & $20 \mathrm{wt} \%$ EVA $+80 \mathrm{wt} \%$ PHB \\
\hline
\end{tabular}

first and, once it was melted at $180^{\circ} \mathrm{C}$, the antioxidant and EVA were added. The blend was kept at $180^{\circ} \mathrm{C}$ and mixed manually with spatula during 10 15 minutes until homogeneous mixture was obtained. The temperature for preparing the blends was chosen by considering that, according manufacturer's data, the melting of PHB is produced at $165-170^{\circ} \mathrm{C}$. Different EVA+PHB blends were prepared and their compositions are shown in Table 2.

\subsection{Experimental techniques}

\section{Differential scanning calorimetry (DSC)}

The compatibility and structure of EVA, PHB and EVA+PHB blends were determined in DSC TA Q100 equipment (TA Instruments, New Castle, DE, USA) under nitrogen atmosphere (flow : $50 \mathrm{~mL} / \mathrm{min}$ ). $10 \mathrm{mg}$ of sample were placed in closed aluminum pans and the temperature was decreased to $-80^{\circ} \mathrm{C}$; then, in order to remove the thermal history, a first heating run was performed from -80 up to $200^{\circ} \mathrm{C}$ by using a heating rate of $10^{\circ} \mathrm{C} / \mathrm{min}$. Afterwards, the sample was cooled down from 200 to $-80^{\circ} \mathrm{C}$ by using a cooling rate of $10^{\circ} \mathrm{C} / \mathrm{min}$, and, finally, a second heating run was carried out from -80 to $200^{\circ} \mathrm{C}$ by using a heating rate of $10^{\circ} \mathrm{C} / \mathrm{min}$. The crystallization of the blends was determined from DSC cooling run, and their melting and glass transition temperatures were determined from the second DSC heating run.

\section{$X$-ray diffraction $(X R D)$}

The crystallinity of EVA, PHB and EVA+PHB blends was determined in Bruker D8-Advance diffractometer (Bruker AXS Inc, Madison, Wisconsin, USA) provided with Kristalloflex K 760-80F X-ray generator. $\mathrm{Cu} \mathrm{K} \alpha$ radiation $(40 \mathrm{~mA} ; \lambda=0.154 \mathrm{~nm} ; 40 \mathrm{kV}$ ) was used in the range of $2 \theta$ from 5 to $90^{\circ}$ recorded in steps of $0.05^{\circ}$ at a scanning rate of $1 \%$ min.

\section{Confocal laser microscopy}

Spherulites in PHB and EVA+PHB blends were analyzed in Zeiss LSM 800 confocal laser microscope (Oberkochen, Baden-Württemberg, Germany) provided with Airyscan; magnifying lens x63, polarized light and $488 \mathrm{~nm}$ laser diode were used. Micrographs were processed with ZEN 2.1 software (Oberkochen, Baden-Württemberg, Germany). $0.1 \mathrm{~g}$ solid sample was placed on glass slide for microscopy and heated at $180^{\circ} \mathrm{C}$ in heating plate. When the sample was softened, a coverslip was placed over the sample and pressed slightly to create a thin film of about $50 \mu \mathrm{m}$ thick. Finally, the sample was cooled down to room temperature and one drop of oil was placed over the coverslip to obtain an adequate contrast in the micrographs.

\section{Dynamic mechanical thermal analysis (DMA)}

The viscoelastic properties and compatibility of EVA, $\mathrm{PHB}$ and $\mathrm{EVA}+\mathrm{PHB}$ blends were determined in DMA Q800 equipment (TA Instruments, New Castle, DE, USA). Rectangular test samples with dimensions of $17 \times 13 \times 3 \mathrm{~mm}$ were prepared as follows. $3 \mathrm{~g}$ blend were placed between two polytetrafluorethylene (PTFE) films. The thickness of the sample was controlled by attaching two steel pieces of $3 \mathrm{~mm}$ on the sides. The blend between the PTFE films was placed in hot plate hydraulic press at $180^{\circ} \mathrm{C}$ applying a pressure of $4 \mathrm{~kg} / \mathrm{cm}^{2}$ during 10 seconds. For avoiding the rupture of the sample (some blends were too stiff), while being hot, the blend film was cut in rectangular pieces with the desired dimensions. Twopoint flexural (single cantilever) geometry was used, the amplitude was $30 \mu \mathrm{m}$, the oscillation frequency was $1 \mathrm{~Hz}$, and the minimum initial force was set to $1 \mathrm{~N}$. A temperature scan from -100 up to $200^{\circ} \mathrm{C}$ was carried out by using a heating rate of $5^{\circ} \mathrm{C} / \mathrm{min}$; however, most of the blends lost dimensional stability above $60^{\circ} \mathrm{C}$.

\section{Plate-plate rheology}

The rheological and viscoelastic properties at high temperature of EVA and some EVA+PHB blends were determined in Discovery HR-2 hybrid rheometer (TA Instruments, New Castle, DE, USA) by using plate-plate geometry under shear stresses; temperature was controlled with Peltier system and upper steel plate of $20 \mathrm{~mm}$ diameter was used. The gap was 
set to $0.4 \mathrm{~mm}$ and the oscillation frequency was $1 \mathrm{~Hz}$. The blends were heated to $180^{\circ} \mathrm{C}$ and the temperature was decreased to $-15^{\circ} \mathrm{C}$ by using a cooling rate of $5^{\circ} \mathrm{C} / \mathrm{min}$.

\section{Tack}

The tack, i.e. immediate adhesion, of EVA, PHB and $\mathrm{EVA}+\mathrm{PHB}$ blends was determined by using the probe tack method in Texture Analyzer TA.XT2i (Stable Micro Systems, Surrey, UK). Flat end cylindrical steel probe of $3 \mathrm{~mm}$ diameter was used. The tack was measured at different temperatures controlled by home-made thermostatic chamber. For measuring tack, polymer films of $200 \mu$ m thick were prepared on stainless steel plate of dimensions $60 \times 60 \mathrm{~mm}$ by heating at $180^{\circ} \mathrm{C}$ followed by pressing at $4 \mathrm{~kg} / \mathrm{cm}^{2}$ during 10 seconds in hydraulic hotplate press (Francisco Muñoz Irles C.B., Petrer, Spain). The probe tack method consists in approaching the test probe to the surface of the film at a rate of $0.1 \mathrm{~mm} / \mathrm{s}$, and once the probe contacted the surface of the film, a force of $5 \mathrm{~N}$ was applied during 1 second; then, the test probe was pulled out at a pulling rate of $10 \mathrm{~mm} / \mathrm{s}$. The stress-strain curves were obtained at each temperature and the maximum stress of the curve was taken as the tack or immediate adhesion. At least three replicates per sample were measured and averaged.

\section{$180^{\circ}$ peel adhesion test}

The final adhesion (i.e. one hour after joint formation) of EVA, PHB and EVA+PHB blends were evaluated by $180^{\circ}$ peel test (Figure 1). The substrates used were aluminum 5754 plate of dimensions $150 \times 30 \times 1.5 \mathrm{~mm}$ and flexible polyethylene terephthalate (PET) or flexible polypropylene (PP) film of dimensions $210 \times 30 \times 0.10 \mathrm{~mm}$. The adhesive joints were made by placing the aluminum 5754 plate over heating plate at $180^{\circ} \mathrm{C}$, applying the blend over it and, once melted, it was spread by means of a spatula; then, PET or PP film was placed on top of the melted blend and immediately pressed at $4 \mathrm{~kg} / \mathrm{cm}^{2}$ during 10 seconds in hydraulic press (Muver, Francisco Muñoz Irles C.B., Petrer, Spain). After 1 hour, the adhesive joints were tested following ASTM D 903 standard in universal testing machine Instron 4411 (Instron, Buckinghamshire, UK), a pulling rate of $152 \mathrm{~mm} / \mathrm{min}$ was used. Five replicates were tested and averaged.

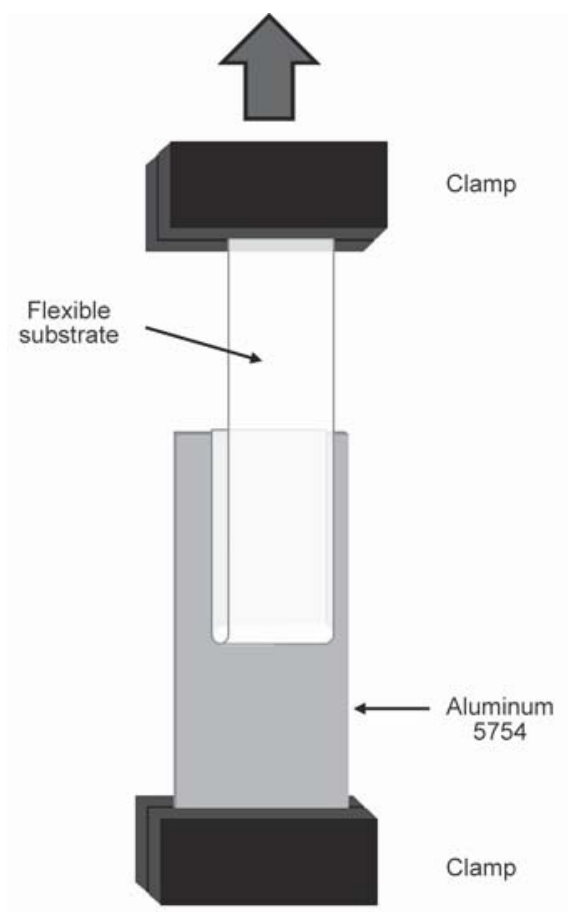

Figure 1. Scheme of $180^{\circ}$ peel test. Flexible substrate: PP or PET film.

\section{Results and discussion \\ 3.1. Characterization of EVA+PHB blends}

The compatibility of EVA+PHB blends was assessed by DSC. Previous studies [21-24] have shown the incompatibility between PHB and EVA. Thus, Gassner and Owen [21] found that the partially crystalline solid blends of PHB and EVA showed two glass transitions and two melting regions due to the existence of two separate phases, the dynamic modulus and failure strength were strongly affected by the blend composition. Thus, in blends with less than $70 \mathrm{wt} \%$ PHB, the behavior was dominated by the softer EVA phase that formed a continuous matrix in which PHB domains were embedded. Similarly, Yoon et al. [22] studied the miscibility of blends of PHB and EVA containing 70$85 \mathrm{wt} \%$ vinyl acetate, and they concluded that the blend of PHB and EVA containing $70 \mathrm{wt} \%$ vinyl acetate was immiscible, and the glass transition temperature, the melting temperature and the spherulite growth rate under isothermal crystallization conditions were independent of the blend composition. On the other hand, El-Taweel et al. [23] prepared biodegradable polymer blends of PHB and EVAs with vinyl acetate contents from 40 to $91 \mathrm{wt} \%$, and they found that PHB/EVA91 blend was the only completely miscible whereas all other were immiscible.

Figure 2 shows the DSC thermograms corresponding to the cooling run for EVA, PHB and EVA/PHB 


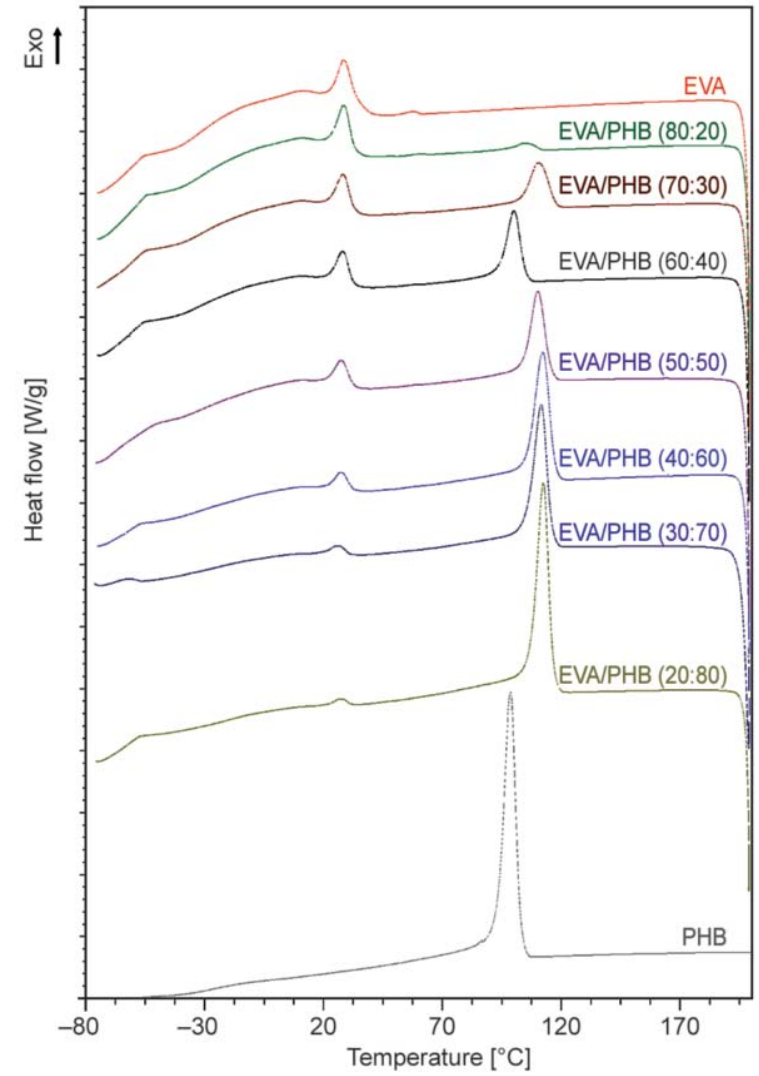

Figure 2. DSC thermograms corresponding to the cooling run of EVA, PHB and EVA/PHB blends.

blends. The maximum of the exothermic crystallization peak of pure PHB occurs at $99^{\circ} \mathrm{C}$ with an enthalpy of crystallization of $39 \mathrm{~J} / \mathrm{g}$, and the one of the polyethylene domains in pure EVA occurs at $29^{\circ} \mathrm{C}$ with an enthalpy of crystallization of $57 \mathrm{~J} / \mathrm{g}$ (Table 3 ). DSC thermogram of the same PHB used in this study (Mirel F3002) has been reported in a previous study [25] in which the crystallization temperature was $116^{\circ} \mathrm{C}$ which is higher than the one obtained in this study $\left(99^{\circ} \mathrm{C}\right)$. The smaller crystallization temperature of Mirel F3002 obtained in our study can be ascribed to some thermal degradation produced during the preparation of the blends and/or during the first
DSC heating run. In fact, in reference [25] the melting temperatures of Mirel F3002 were 158 and $168^{\circ} \mathrm{C}$ and its melting enthalpy was $81 \mathrm{~J} / \mathrm{g}$. In our study, during the first DSC heating run, the melting temperatures of PHB were 149 and $159^{\circ} \mathrm{C}$ and the melting enthalpy was $31 \mathrm{~J} / \mathrm{g}$, all them are lower than the ones in reference [25]. Therefore, PHB seems being degraded under melting conditions during preparation of the blends leading to a reduction of molecular mass which should affect its crystallization and distribution in EVA matrix.

All EVA/PHB blends show the crystallization temperatures of EVA and PHB phases (Figure 2). Whereas the crystallization temperature of the polyethylene domains of EVA phase is almost similar $\left(26-29^{\circ} \mathrm{C}\right)$ in all blends, the crystallization temperature of PHB phase shifts to higher temperature (from 99 to 110 $112^{\circ} \mathrm{C}$ ) irrespective of the EVA content in the blends; however, EVA/PHB (80:20) and EVA/PHB (60:40) blends are exceptional because of less important increase of the crystallization temperature of PHB phase $\left(100-104{ }^{\circ} \mathrm{C}\right)$ is produced (Table 3$)$. In a previous study [23] it has been reported that the blend of $50 \mathrm{wt} \%$ EVA with vinyl acetate content of 40 and $50 \mathrm{wt} \%$ PHB was not compatible and the melting temperature of the blend was close to that of pure PHB; furthermore, in that blend the decrease in the crystallization temperature of PHB was ascribed to the accumulation of EVA in intra-spherulitic regions of PHB [23]. On the other hand, the decrease in the molecular mass of PHB caused by melting should affect its crystallization and should favour its distribution in EVA matrix in the blends. Furthermore, interfacial interactions between EVA and PHB phases can be produced in EVA/PHB blends, leading to higher crystallization temperature with respect to pure PHB, even for low amounts of EVA. Interestingly, the same crystallization temperatures for EVA and PHB

Table 3. Enthalpies and temperatures of crystallization of EVA, PHB and EVA/PHB blends. DSC cooling run.

\begin{tabular}{|l|c|c|c|c|c|}
\hline \multicolumn{1}{|c|}{ Blend } & $\begin{array}{c}\mathbf{P H B} \\
{[\mathbf{w t} \%]}\end{array}$ & $\begin{array}{c}\Delta \boldsymbol{H}_{\mathbf{c ~ E V A}} \\
{[\mathbf{J} / \mathbf{g}]}\end{array}$ & $\begin{array}{c}\boldsymbol{T}_{\mathbf{c ~ E V A}} \\
{\left[{ }^{\circ} \mathbf{C}\right]}\end{array}$ & $\begin{array}{c}\Delta \boldsymbol{H}_{\mathbf{c ~ P H B}} \\
{[\mathbf{J} / \mathbf{g}]}\end{array}$ & $\begin{array}{c}\boldsymbol{T}_{\mathbf{c}} \text { PHB } \\
{\left[{ }^{\circ} \mathbf{C}\right]}\end{array}$ \\
\hline EVA & 0 & 57 & 29 & - & - \\
\hline EVA/PHB (80:20) & 20 & 42 & 29 & 2 & 104 \\
\hline EVA/PHB (70:30) & 30 & 34 & 28 & 10 & 110 \\
\hline EVA/PHB (60:40) & 40 & 31 & 28 & 11 & 100 \\
\hline EVA/PHB (50:50) & 50 & 21 & 27 & 16 & 110 \\
\hline EVA/PHB (40:60) & 60 & 20 & 27 & 21 & 112 \\
\hline EVA/PHB (30:70) & 70 & 11 & 26 & 23 & 111 \\
\hline EVA/PHB (20:80) & 80 & 7 & 27 & 29 & 112 \\
\hline PHB & 100 & - & - & 39 & 99 \\
\hline
\end{tabular}


domains appear in EVA/PHB blends containing more than $50 \mathrm{wt} \% \mathrm{PHB}$, pointing to less miscibility of EVA and PHB phases. On the other hand, the crystallization enthalpies of PHB and EVA domains in the blends containing 30-70 wt \% PHB (Table 3) are lower than expected if they were completely immiscible. For example, considering the crystallization enthalpy $\left(\Delta H_{\mathrm{c}}\right)$ values of pure polymers, completely miscible EVA/PHB (50:50) blend should have $\Delta H_{\mathrm{c}}$ value of $29 \mathrm{~J} / \mathrm{g}$ for EVA phase and $\Delta H_{\mathrm{c}}$ value of $20 \mathrm{~J} / \mathrm{g}$ for PHB phase, but the experimental values are lower (21 and $16 \mathrm{~J} / \mathrm{g}$ respectively). Therefore, the existence of interfacial interactions between EVA and PHB phases and the change in the crystallinity of PHB in EVA/PHB blends are confirmed, this is consistent with partial miscibility. In fact, Yoon et al. [26] have shown that although polylactic acid (PLA)+EVA blend was immiscible according DSC results, the Flory-Huggins interaction parameter of the blend was negative, indicating that the blend was miscible.

Figure 3 shows the DSC thermograms obtained from the second heating run for PHB, EVA and EVA/PHB blends. DSC thermogram of pure EVA shows the glass transition temperature at $-33^{\circ} \mathrm{C}$ and wide endothermic peak with two overlapped melting peaks at 22 and $54{ }^{\circ} \mathrm{C}$ due to the softening of the vinyl acetate domains [27]. On the other hand, DSC thermogram of pure PHB shows the glass transition temperature at $-21^{\circ} \mathrm{C}$ and two endothermic peaks at $131{ }^{\circ} \mathrm{C}$ (due to the melting of imperfect crystals) and $147^{\circ} \mathrm{C}$ (due to the melting of perfect crystals produced by recrystallization). DSC thermogram of the same PHB used in this study (Mirel F3002) has been reported earlier [25] and the glass transition temperature was $12^{\circ} \mathrm{C}$, and the melting temperatures were 158 and $168^{\circ} \mathrm{C}$, all higher than the ones obtained in our study. In our study, during the first DSC heating run, the glass transition temperature of PHB was $-6^{\circ} \mathrm{C}$ and the melting temperatures were 149 and $159^{\circ} \mathrm{C}$, all relatively similar to the ones obtained in reference [25] but higher than the ones obtained during the second DSC heating run. The higher glass transition temperature and melting temperatures of PHB found in our study confirm that some thermal degradation is produced during the preparation of the blends and during the first DSC heating run.

DSC thermograms of EVA/PHB blends show the glass transition of EVA phase but the one of PHB cannot be observed clearly because is within the

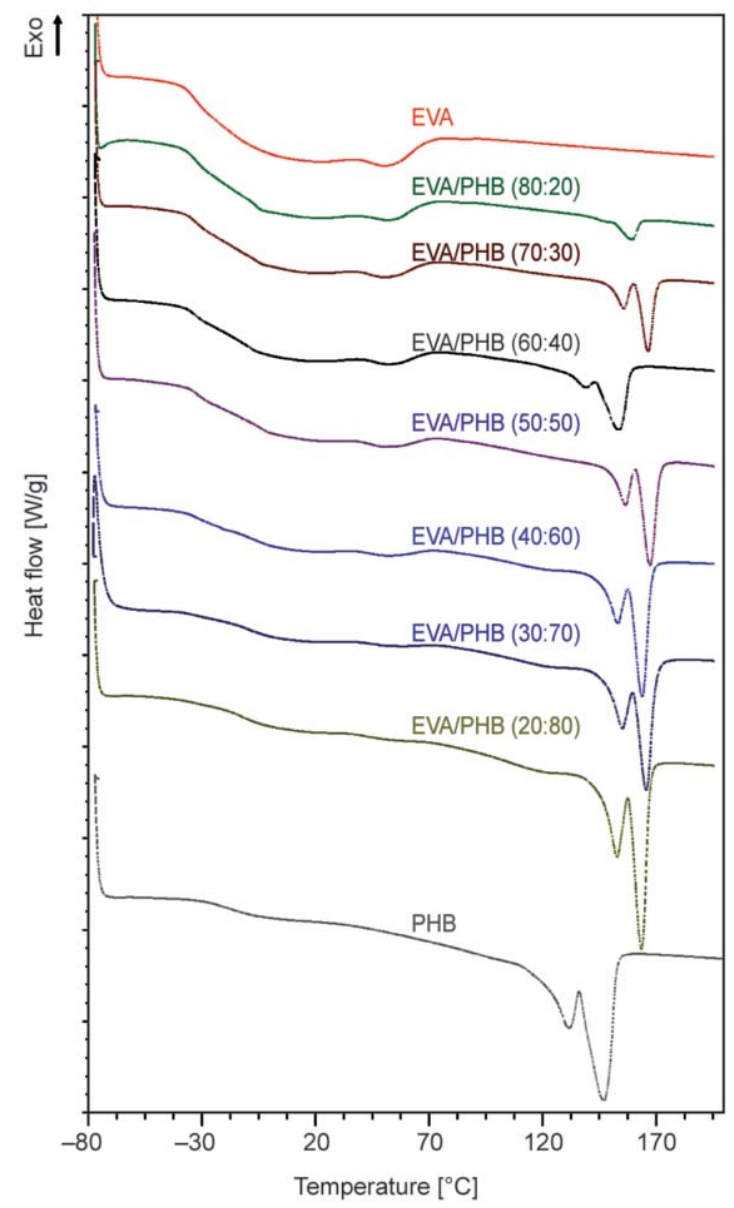

Figure 3. DSC thermograms of EVA, PHB and EVA/PHB blends. Second heating run.

melting peak of EVA (EVA/PHB (20:80) is an exception) (Figure 3). Addition of PHB shifts the melting peak of EVA at $22^{\circ} \mathrm{C}$ to lower temperature irrespective of the PHB content in the blend, but the melting peak of EVA at $54{ }^{\circ} \mathrm{C}$ is not affected by adding PHB (EVA/PHB (70:30) is an exception) (Table 4). Furthermore, the two melting peaks of pure PHB shift to higher temperatures in all blends (from 131 to $138-156^{\circ} \mathrm{C}$ and from 147 to $154-167^{\circ} \mathrm{C}$ ), this indicating better miscibility which can be favoured by the reduction in molecular mass of PHB during melting. The increase is less important in the blends containing $40 \mathrm{wt} \%$ or less PHB (EVA/PHB (70:30) is an exception); furthermore, the melting temperatures of the blends containing more than $50 \mathrm{wt} \%$ PHB are very similar (Table 4) and much higher for the PHB phase. On the other hand, the changes in the melting temperatures may indicate the existence of interactions between PHB and EVA phases in EVA/ PHB blends containing less than $50 \mathrm{wt} \%$ PHB, likely leading to smaller crystalline phases of PHB. EVA/ PHB (80:20) and EVA/PHB (60:40) blends are 
Table 4. Some parameters obtained from the DSC thermograms of EVA, PHB and EVA/PHB blends. Second heating run.

\begin{tabular}{|c|c|c|c|c|c|}
\hline Blend & $\begin{array}{c}\boldsymbol{T}_{\mathbf{g}} \\
{\left[{ }^{\circ} \mathbf{C}\right]}\end{array}$ & $\begin{array}{c}\Delta H_{\mathrm{m} \text { EVA }} \\
{[\mathrm{J} / \mathrm{g}]}\end{array}$ & $\begin{array}{c}T_{\mathrm{m} \mathrm{EVA}} \\
{\left[{ }^{\circ} \mathrm{C}\right]}\end{array}$ & $\begin{array}{c}T_{\mathrm{m} \text { PHB }} \\
{\left[{ }^{\circ} \mathbf{C}\right]}\end{array}$ & $\begin{array}{c}\Delta H_{\mathrm{m}} \mathrm{PHB} \\
{[\mathrm{J} / \mathrm{g}]}\end{array}$ \\
\hline EVA & -33 & 40 & $22 / 54$ & - & - \\
\hline EVA/PHB (80:20) & -33 & 34 & $14 / 55$ & $147 / 159$ & 2 \\
\hline EVA/PHB (70:30) & -31 & 26 & $14 / 49$ & $156 / 166$ & 11 \\
\hline EVA/PHB (60:40) & -33 & 26 & $12 / 54$ & $138 / 154$ & 8 \\
\hline EVA/PHB (50:50) & -32 & 19 & $15 / 53$ & $156 / 167$ & 13 \\
\hline EVA/PHB (40:60) & -32 & 12 & $12 / 52$ & $154 / 166$ & 12 \\
\hline EVA/PHB (30:70) & -33 & 8 & $12 / 53$ & $155 / 166$ & 13 \\
\hline EVA/PHB (20:80) & -22 & 6 & $6 / 53$ & $153 / 164$ & 20 \\
\hline PHB & -21 & - & - & $131 / 147$ & 25 \\
\hline
\end{tabular}

exceptional because of lower first melting temperature of PHB $\left(138-147^{\circ} \mathrm{C}\right)$ is obtained (Table 4).

Both the melting temperature $\left(T_{\mathrm{m}}\right)$ and the crystallization temperature $\left(T_{\mathrm{c}}\right)$ associated to $\mathrm{PHB}$ phase in EVA/PHB blends shift to higher temperature (Figures 2 and 3) due to the existence of physical interactions between EVA and PHB phases. A recent study [28] established that PHB crystallized forming antiparallel helical chains between the carbonyl $(\mathrm{C}=\mathrm{O})$ and methyl $\left(\mathrm{CH}_{3}\right)$ groups of the backbone of pure PHB. Because of $\mathrm{CH}_{3}$ and $\mathrm{C}=\mathrm{O}$ groups are also present in EVA, interactions between $\mathrm{C}=\mathrm{O}$ and $\mathrm{CH}_{3}$ groups of $\mathrm{PHB}$ and $\mathrm{CH}_{3}$ and $\mathrm{C}=\mathrm{O}$ groups of vinyl acetate domains in EVA can be produced. Furthermore, ElHadi [29] proposed the existence of physical crosslinking between PHB and different polymers (PLA, polypropylene carbonate - PPC -, polyvinyl acetate $-\mathrm{PVAc})$, and the existence of interactions between the carbonyl $(\mathrm{C}=\mathrm{O})$ and methyl $\left(\mathrm{CH}_{3}\right)$ groups between PHB and PLA, and between PHB and PVAc in polymer blends have been supported in several studies [30-36].

The crystallinity of EVA, PHB and EVA/PHB blends was determined by $\mathrm{X}$-ray diffraction. Figure 4 shows

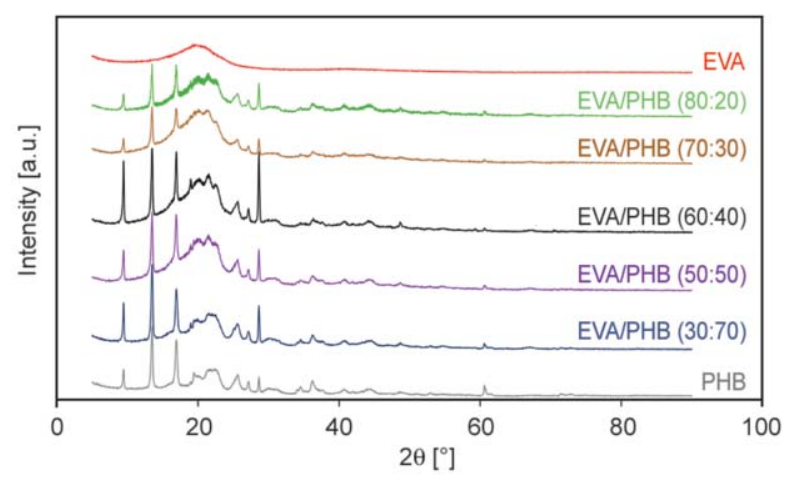

Figure 4. X-ray diffractograms of EVA, PHB and EVA/PHB mixtures. the X-ray diffractograms of PHB, EVA and EVA/PHB blends. The wide $\mathrm{X}$-ray diffraction peak in pure EVA indicates absence of crystallinity. Pure PHB shows semicrystalline structure evidenced by the intense peaks at $2 \theta$ values of 13.3 and $16.9^{\circ}$, associated to orthorhombic crystalline structure $[37,38]$. Due to overlapping with the wide diffraction peak of EVA, the wide peak at $2 \theta$ values of $21-22^{\circ}$ of $\alpha$ phase of pure PHB is not observed in EVA/PHB blends. On other hand, the peak at $2 \theta$ values of $20^{\circ}$ is associated to $\beta$ phase of pure PHB [28]. All EVA/PHB blends show the crystallinity due to PHB phase and they have similar diffraction peaks but with different intensities, in agreement with the evidences shown by DSC. Figure 5 shows, as typical example, the variation of the intensities of the diffraction peaks of EVA/PHB blends at $2 \theta$ values of 13.3 and $16.9^{\circ}$ as a function of their PHB content. Similar intensities appear in EVA/PHB blends containing PHB amounts higher than $40 \mathrm{wt} \%$ and they are similar to the ones of pure PHB, indicating dominant structure of PHB phase and important phase separation. However, the intensity of the diffractions peaks in EVA/PHB blends containing less than $40 \mathrm{wt} \%$ PHB is lower than in

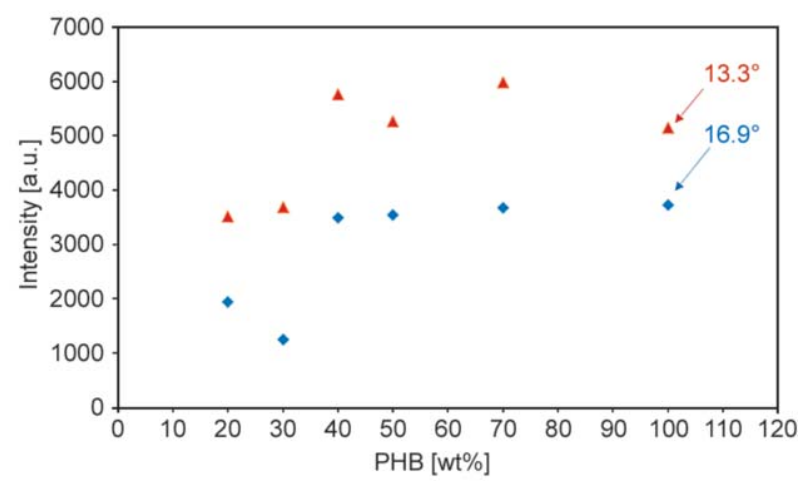

Figure 5. Variation of the intensity of the diffraction peaks of EVA/PHB blends at $2 \theta$ values of 13.3 and $16.9^{\circ}$ as a function of their PHB content. 


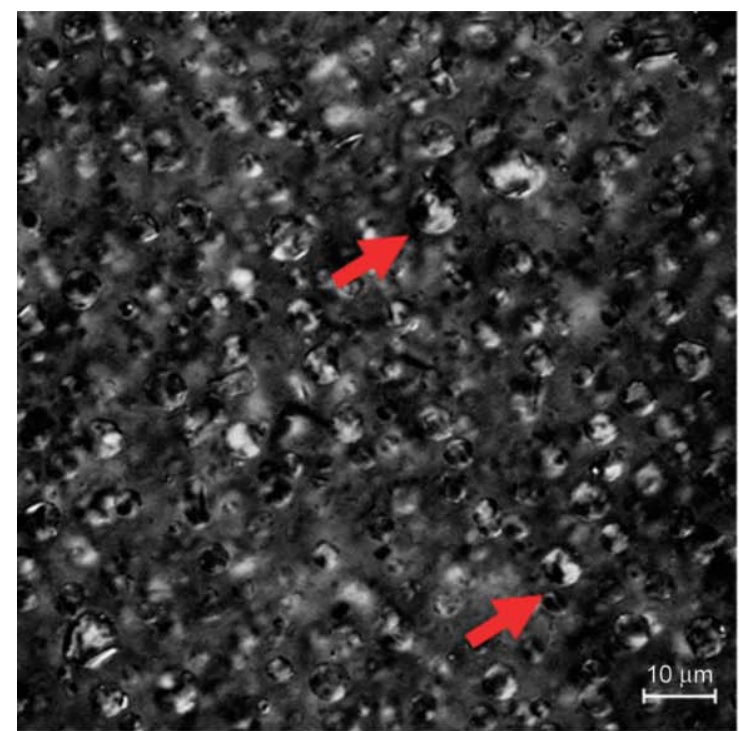

$\operatorname{EVA} / \mathrm{PHB}(80: 20)$

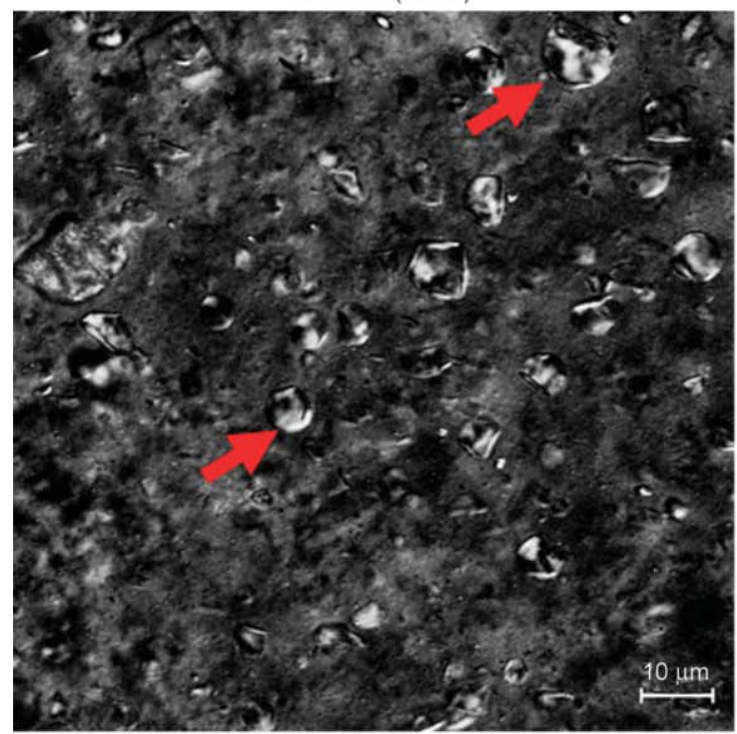

EVA/PHB $(60: 40)$

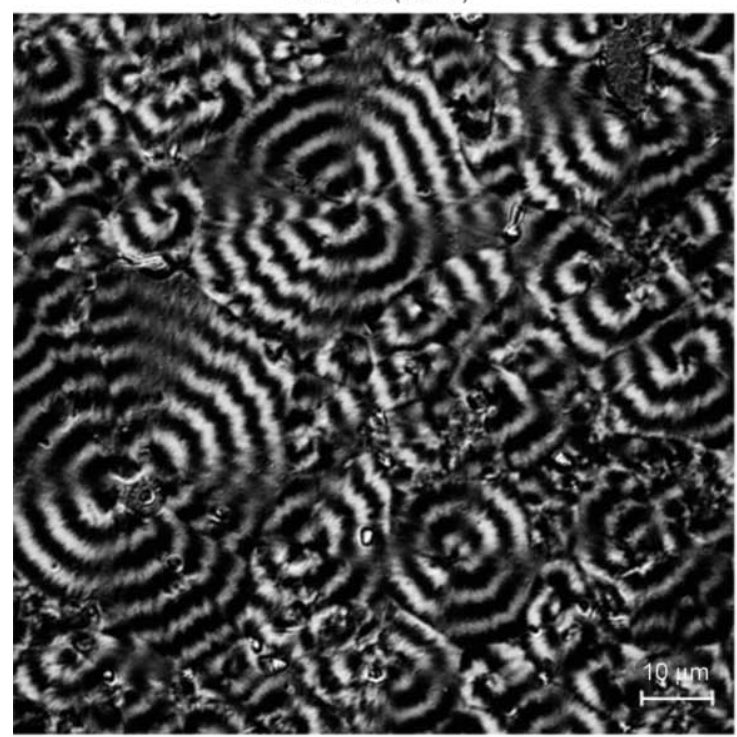

EVA/PHB (30:70)

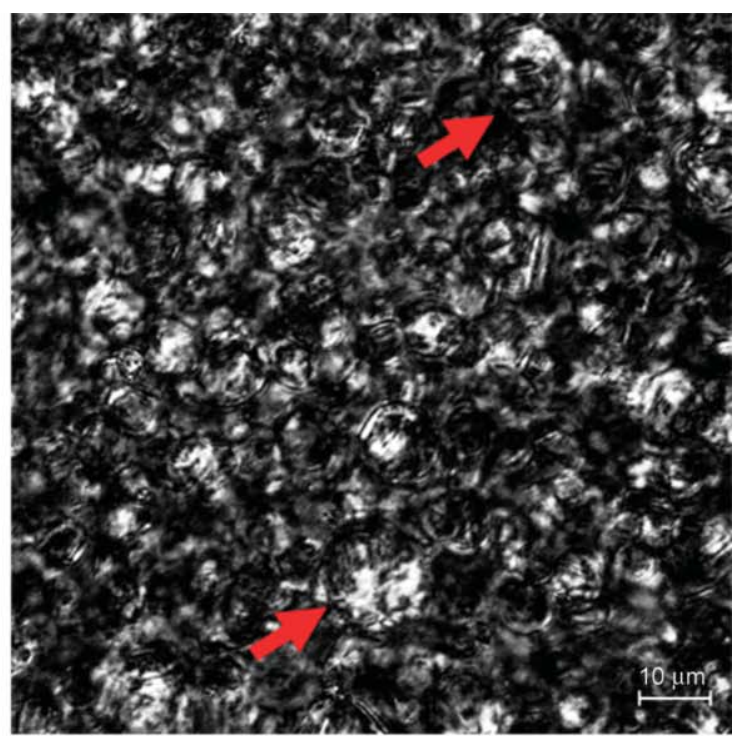

EVA/PHB (70:30)

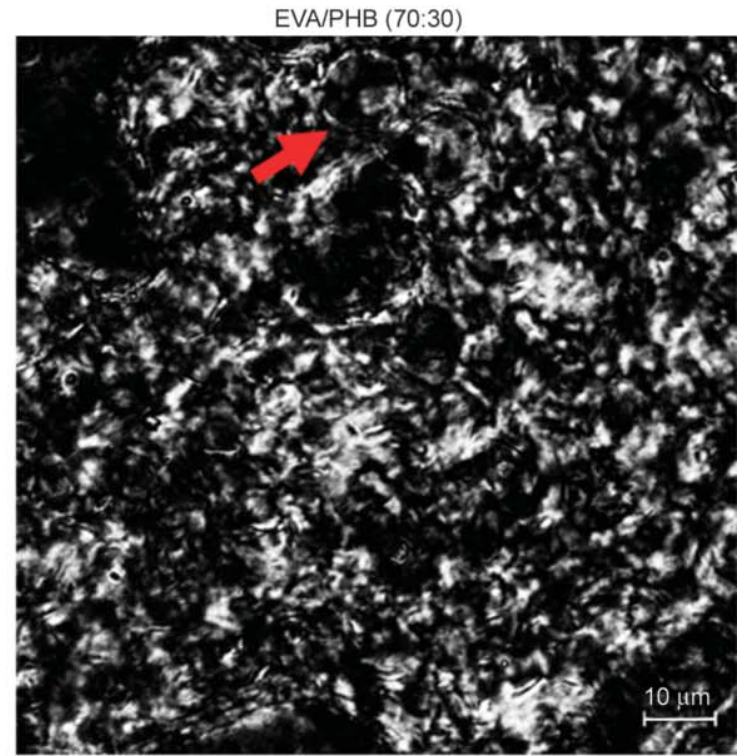

EVA/PHB (50:50)

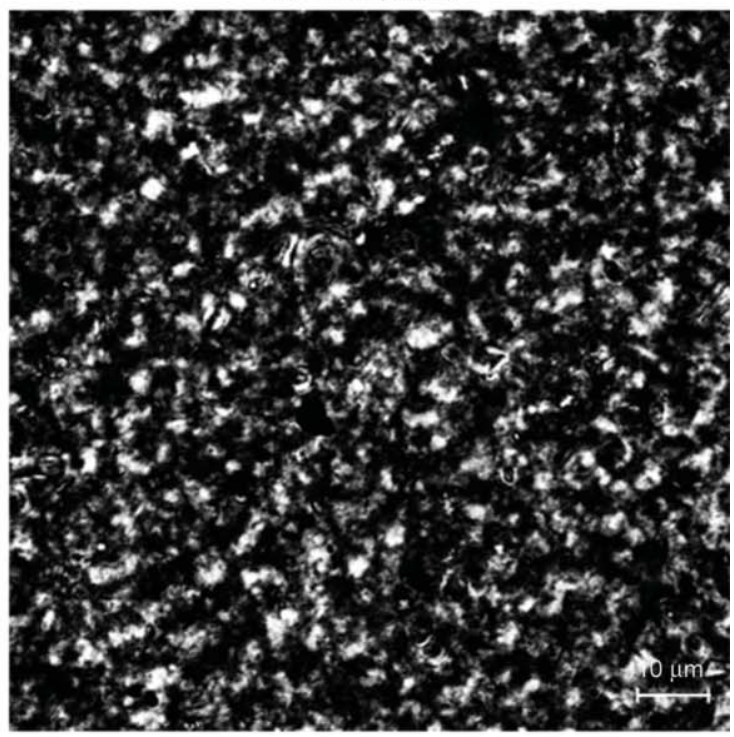

PHB

Figure 6. Confocal laser micrographs of PHB and EVA/PHB blends. 
pure PHB and decreases by increasing their EVA content. Interestingly, the intensities of the diffraction peaks in EVA/PHB (70:30) are lower than expected, likely due to more net interfacial interactions between EVA and PHB phases, in agreement with DSC results (Tables 3 and 4).

The existence of crystalline structures in PHB and EVA/PHB blends was also evidenced by confocal laser microscopy. Spherulites are absent in pure EVA whereas pure PHB shows small spherulites of less than $5 \mu \mathrm{m}$ diameter (Figure 6). Addition of $30 \mathrm{wt} \%$ EVA increases the spherulites size $(40-80 \mu \mathrm{m})$ of PHB phase, indicating that EVA worsens the crystallization of PHB. On the other hand, the size and distribution of the spherulites in EVA/PHB (50:50) blend is similar than in pure PHB (Figure 6), although some bigger spherulites of about $10 \mu \mathrm{m}$ diameter are noticed. Micrographs of EVA/PHB (80:20) and EVA/ PHB (60:40) show the presence of PHB spherulites disseminated in the amorphous EVA matrix, and the increase in PHB content causes the formation of lower number but larger spherulites (Figure 6) due to the worsening of the crystallization of PHB. Interestingly, EVA/PHB (70:30) micrograph shows higher number and larger spherulites than EVA/PHB (80:20) and EVA/PHB (60:40), confirming higher miscibility, in agreement with the evidences provided by DSC and X-ray diffraction experiments. Therefore, the structure of EVA/PHB (70:30) is different from that of the other EVA/PHB blends containing less than $50 \mathrm{wt} \%$ PHB, likely due to the existence of more net interfacial interactions and higher compatibility between EVA and PHB phases.

The existence of interactions between EVA and PHB in the blends is also evidenced by changes in their viscoelastic properties which were measured by plate-plate rheology. Figure 7 shows the variation of the storage modulus $\left(G^{\prime}\right)$ as a function of the temperature for EVA and EVA/PHB blends containing less than $50 \mathrm{wt} \%$ PHB. The variation of $G^{\prime}$ as a function of the temperature is similar for pure EVA and EVA/ PHB blends containing 20 and $30 \mathrm{wt} \%$ PHB. The appearance of crystallinity by cooling down the blend should be noticed as a sudden increase in $G^{\prime}$ value. Although EVA/PHB (70:30) blend shows similar viscoelastic behavior than pure EVA, its $G^{\prime}$ values are higher in all range of temperature and the crystallinity of PHB domains is not noticed, in agreement with the findings of Choi et al. [39]. Therefore, the absence of crystallization in the rheological curves of

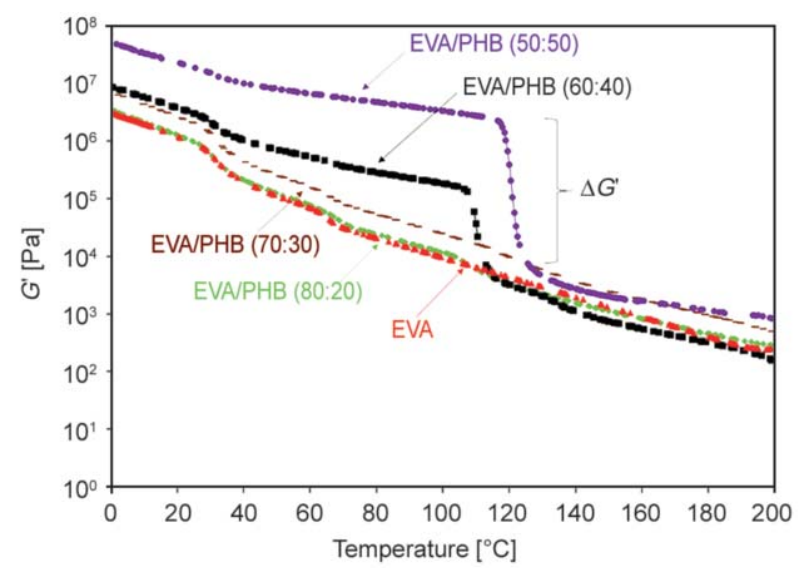

Figure 7. Variation of the storage modulus $\left(G^{\prime}\right)$ as a function of the temperature for EVA and EVA/PHB blends.

EVA/PHB blends containing 20 and $30 \mathrm{wt} \%$ PHB indicates good miscibility between EVA and PHB, in agreement with the evidences shown by DSC and $\mathrm{X}$-ray diffraction. However, the addition of 40 or $50 \mathrm{wt} \%$ PHB increases the $G^{\prime}$ values noticeably, more markedly by increasing the amount of PHB, and the sudden increase in $G^{\prime}$ value at $110-131{ }^{\circ} \mathrm{C}$ corresponds to the crystallization of the immiscible PHB phase in the blends. The higher the PHB content, the higher the increase in the storage modulus of the blend and the higher the temperature at which it is produced, indicating the existence of two separated EVA and PHB phases in EVA/PHB (60:40) and EVA/PHB (50:50).

Figure 8 shows the variation of the storage and loss moduli as a function of the temperature for pure EVA, EVA/PHB (70:30) and EVA/PHB (50:50), and all show a cross-over between the storage and loss moduli. Below the cross-over, the elastic behavior is dominant and above the cross-over the viscous behavior is dominant. For pure EVA the moduli are relatively close before and after the cross-over at $64^{\circ} \mathrm{C}$, and EVA/PHB (70:30) blend shows similar crossover value and variation of the moduli with the temperature than pure EVA, indicating miscibility of the PHB phase in EVA matrix. However, the variation of the storage and loss moduli as a function of the temperature for EVA/PHB (50:50) is different and shows a sudden increase of the moduli in the region of the cross-over at $121^{\circ} \mathrm{C}$, the increase is due to the crystallization of the PHB phase in the blend.

The structure of EVA/PHB blends depends on their PHB content, i.e., PHB phase is dominating the structure and properties of the blends containing more than $50 \mathrm{wt} \%$ PHB, whereas these are determined by EVA phase when the PHB content is lower 

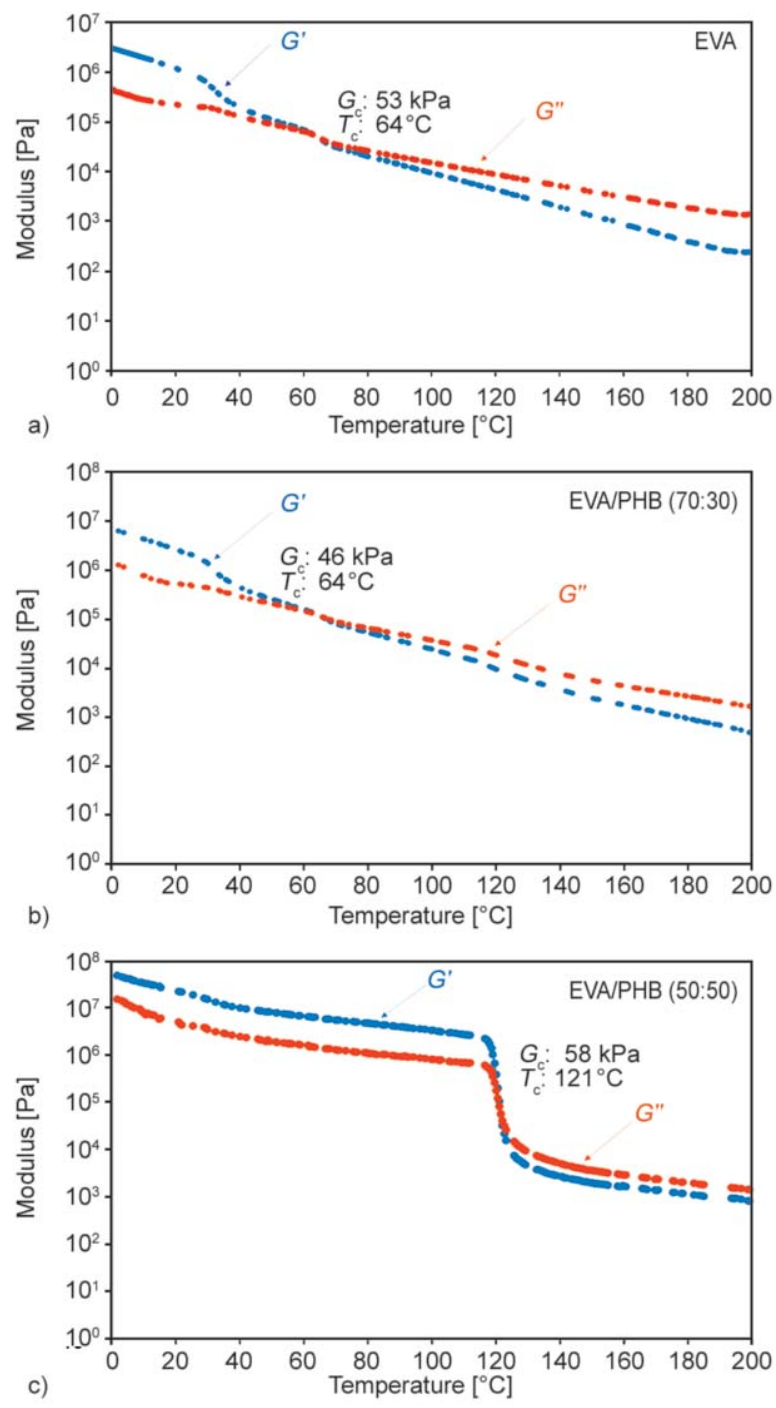

Figure 8. Variation of the storage $\left(G^{\prime}\right)$ and loss $\left(G^{\prime \prime}\right)$ moduli as a function of the temperature for $\operatorname{EVA}(\mathrm{a})$, EVA/PHB (70:30) (b) and EVA/PHB (50:50) (c).

than $50 \mathrm{wt} \%$. DMA has been proven to be useful to evaluate the viscoelastic and structural properties of polymers, and the compatibility of polymer blends as well [40]. The variation of the storage modulus $\left(E^{\prime}\right)$ as a function of the temperature for pure EVA, pure PHB and EVA/PHB blends is shown in Figure 9. The viscoelastic curve of pure EVA shows the glassy region in which the storage modulus is not varying by increasing the temperature, followed by the glass transition region that is produced in a wide range of temperature. After the glass transition region, the rubbery plateau appears and the melting of the vinyl acetate domains in EVA causes sudden decrease of the storage modulus, until noticeable loss of dimensional stability is noticed at $80^{\circ} \mathrm{C}$. On the other hand, pure PHB shows the typical viscoelastic plot of stiff material, i.e. the glassy region is produced in a broad

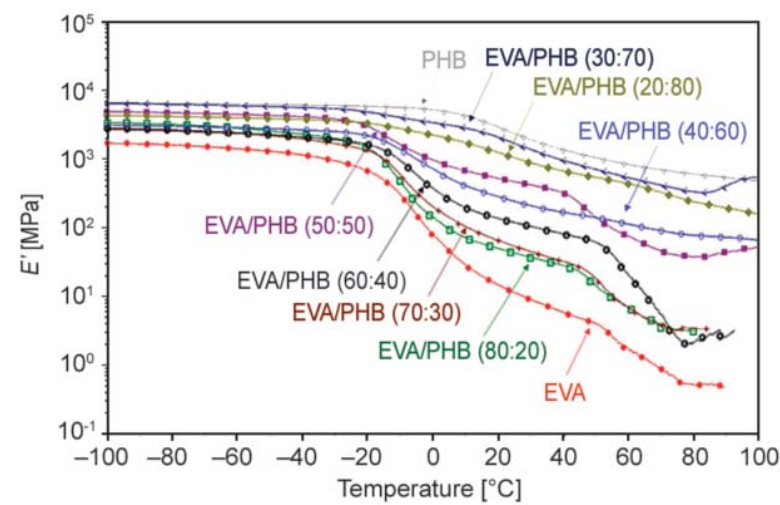

Figure 9. Variation of the storage modulus $\left(E^{\prime}\right)$ as a function of the temperature for EVA, PHB and EVA/PHB blends.

range of temperature followed by the glass transition with very small change in storage modulus and, by increasing the temperature, an extended rubbery plateau with small variation of the storage modulus is noticed. The viscoelastic properties of EVA/PHB blends containing more than $70 \mathrm{wt} \%$ PHB are dominated by the PHB phase and they show very similar variation of the storage modulus as a function of the temperature; however, the viscoelastic properties of EVA/PHB blends containing $30 \mathrm{wt} \%$ or less PHB are dominated by EVA phase, although a significant increase of the storage modulus is produced (Figure 9). EVA/PHB blends containing 40 to $60 \mathrm{wt} \%$ PHB show particular features. Thus, EVA/PHB (50:50) blend shows high storage modulus in the glassy region but the glass transition and the rubbery plateau are clearly differentiated. EVA/PHB (40:60) blend shows lower storage modulus than pure PHB, and the glass transition and the rubbery plateau regions are also clearly differentiated, and EVA/PHB (60:40) blend shows lower storage modulus than pure PHB and the glass transition and the rubbery plateau regions are clearly dominated by EVA phase. Considering that the crystallinity of EVA/PHB blends containing more than $50 \mathrm{wt} \%$ PHB is similar than for pure PHB (Figure 4) and similar variation in the crystallization and melting processes is evidenced by DSC (Figures 2 and 3, Tables 3 and 4), these blends should contain similar PHB phase structure but the size of this phase should be different. However, the structure of EVA/PHB blends containing less than $50 \mathrm{wt} \%$ PHB shows lower crystallinity and the viscoelastic properties are dominated by EVA phase. Furthermore, EVA/PHB (70:30) is an exception, because of viscoelastic properties similar to EVA/PHB (80:20) are obtained. 

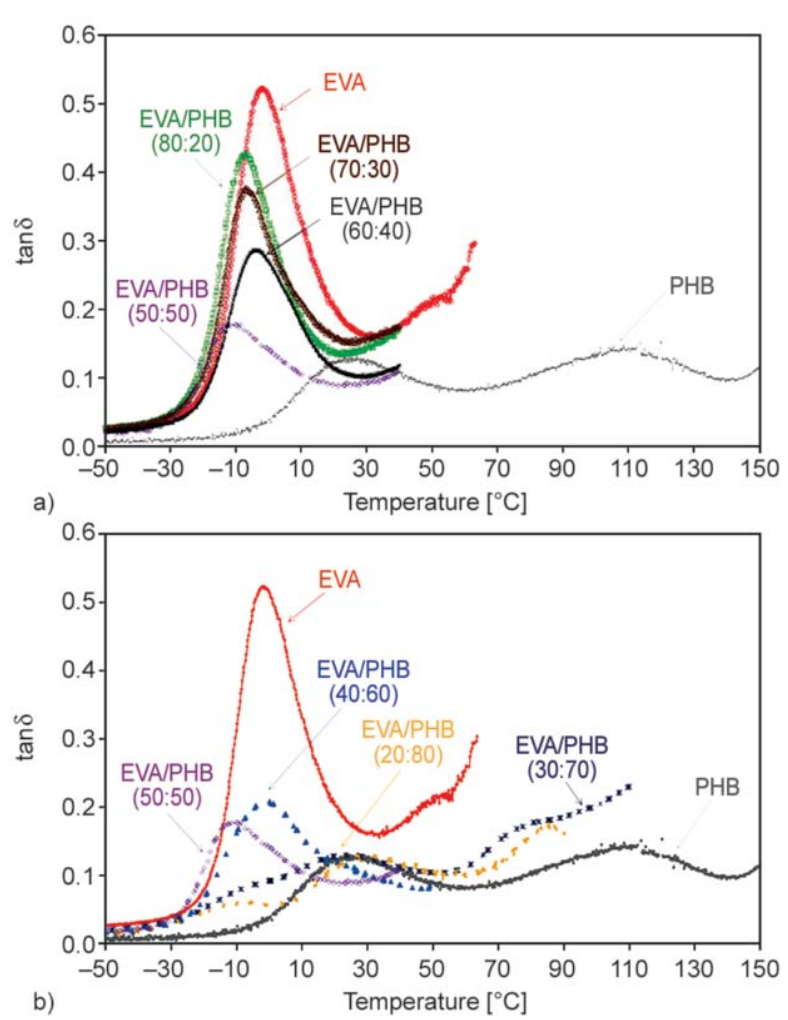

Figure 10. Variation of $\tan \delta$ as a function of the temperature for EVA, PHB and EVA/PHB blends. a) EVA/ PHB blends with more than $50 \mathrm{wt} \%$ EVA, b) EVA/ PHB blends with more less than $50 \mathrm{wt} \%$ EVA

Figure 10 shows the variation of the loss factor $\left(\tan \delta=E^{\prime \prime} / E^{\prime}\right)$ as a function of the temperature for PHB, EVA and EVA/PHB blends. The temperatures of the maxima correspond to the structural relaxations, some of which can be related to the glass transition temperature. Pure EVA shows one structural relaxation at $-3{ }^{\circ} \mathrm{C}$ and pure $\mathrm{PHB}$ shows two structural relaxations at 19 and $109^{\circ} \mathrm{C}$, the last one can be ascribed to the interactions between the polymeric chains in the vicinity of the melting. The glass transition temperature of EVA phase in the blends containing $50 \mathrm{wt} \%$ or less PHB shifts to lower temperature indicating immiscibility. EVA/PHB (40:60) blend shows the same $\tan \delta$ value as EVA/PHB (50:50) but the glass transition temperature is higher because of the structure is dominated by PHB phase. On the other hand, the blends containing 70 and $80 \mathrm{wt} \%$ PHB show three structural relaxations, the one at lower temperature $\left(-9\right.$ to $\left.-11^{\circ} \mathrm{C}\right)$ is associated to EVA phase and the others at $19-23$ and $80-84^{\circ} \mathrm{C}$ correspond to PHB phase. The structural relaxation at $109^{\circ} \mathrm{C}$ of pure PHB is displaced to $80-84^{\circ} \mathrm{C}$ in EVA/PHB (30:70) and EVA/PHB (20:80) blends, indicating the creation of interactions between EVA and PHB phases, i.e. better miscibility.
The values of $\tan \delta$ in the maxima of the plots of EVA+PHB blends of Figure 10 can be related to the interactions between the polymeric chains, i.e., low $\tan \delta$ value or low damping indicates higher storage modulus due to dominant strong interactions between the polymeric chains (stiffness) and less ability to store energy due to lower mobility of the polymeric chains, whereas high $\tan \delta$ value or high damping indicates higher loss modulus and softer material. The value of the maximum of $\tan \delta$ of pure EVA is 0.52 and the ones for PHB are much lower $(0.12-$ 0.13 ) because of its higher stiffness. The addition of PHB decreases the $\tan \delta$ value of EVA in the blends, the decrease is less pronounced in the blends with $50 \mathrm{wt} \%$ or more PHB content. The more marked decrease in $\tan \delta$ corresponds to the blends containing $30-40 \mathrm{wt} \%$ PHB, indicating improved compatibility.

\subsection{Proposed mechanism of the interactions in EVA/PHB blends}

According to the experimental results shown above, the structure of EVA/PHB blends depend on their PHB content, i.e., for amounts of PHB higher than $50 \mathrm{wt} \%$, PHB phase is dominating the structure and the properties of the blends, whereas these are determined by EVA phase when PHB content is lower than $50 \mathrm{wt} \%$. However, the structure and properties of EVA/PHB (70:30) blend is different. The existence of physical interactions between EVA and PHB phases in EVA/PHB blends is evidenced by changes in compatibility, crystallinity and viscoelastic properties. The interactions between EVA or PVAc and PHB or PLA or PPC in polymer blends have been ascribed to the disruption of the interactions between the carbonyl $(\mathrm{C}=\mathrm{O})$ and methyl $\left(\mathrm{CH}_{3}\right)$ groups by weak physical interactions with $\mathrm{C}=\mathrm{O}$ and $\mathrm{CH}_{3}$ groups of PVAc [28-36]. Because of $\mathrm{CH}_{3}$ and $\mathrm{C}=\mathrm{O}$ groups also exists in the vinyl acetate domains in EVA, weak interfacial interactions between $\mathrm{C}=\mathrm{O}$ and $\mathrm{CH}_{3}$ groups of $\mathrm{PHB}$ and $\mathrm{CH}_{3}$ and $\mathrm{C}=\mathrm{O}$ groups of EVA can be produced.

In the blends with PHB content lower than $50 \mathrm{wt} \%$, the addition of EVA increases the spherulite size due to worsening of the crystallization of PHB phase and the creation of interactions between EVA and PHB chains; as a consequence, more pronounced phase separation between the ethylene and vinyl acetate domains in EVA phase are produced (Figure 11a). However, in the blends with PHB content higher than $50 \mathrm{wt} \%$, PHB phase appears in the amorphous 

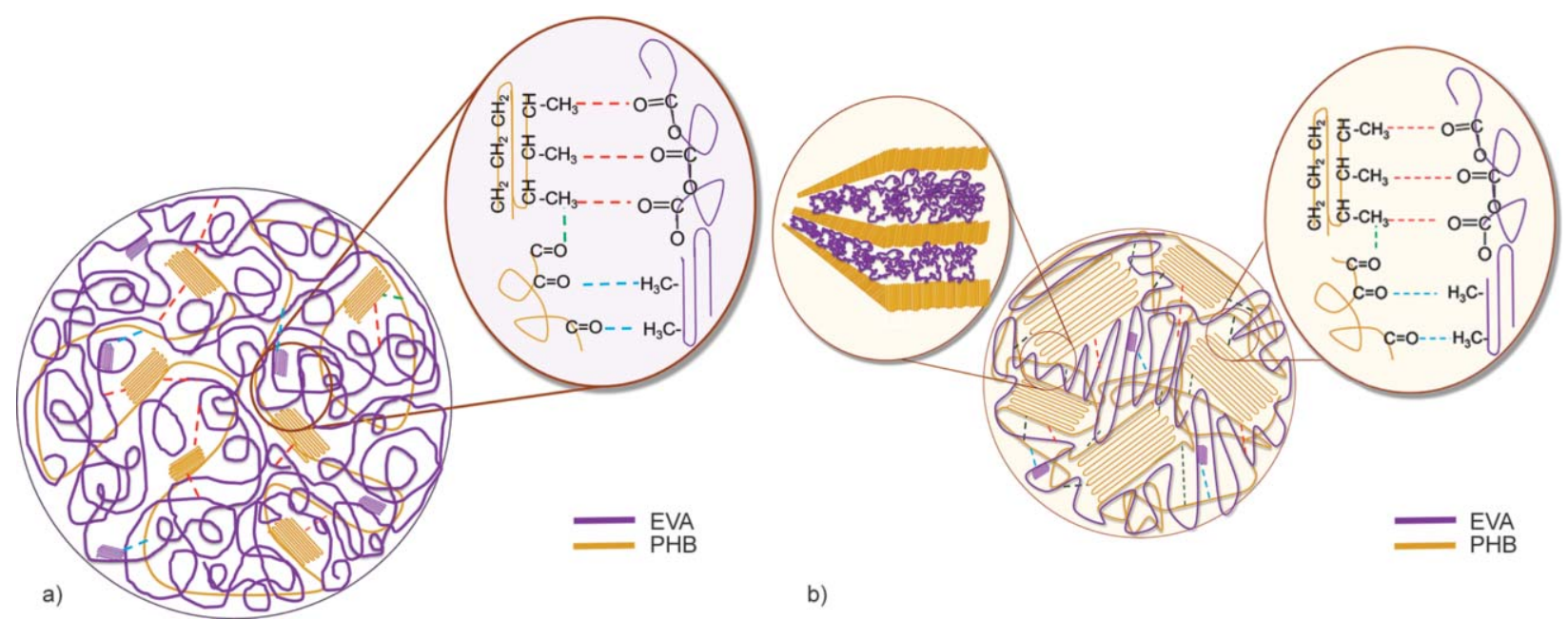

Figure 11. a) Scheme showing the interactions between PHB and EVA phases in blends containing more than $50 \mathrm{wt} \% \mathrm{PHB}$.

b) Scheme showing the interactions between PHB and EVA phases in EVA/PHB (70:30) blend.

EVA matrix and their properties are determined by PHB phase. EVA/PHB (70:30) blend is an exception because of the creation of new more net physical interactions between the carbonyl and methylene groups of vinyl acetate in EVA and PHB than in the other blends, which lead to disruption of ethylene and vinyl acetate domains in EVA phase and, consequently, new structure with different crystallinity, thermal, and viscoelastic properties is produced (Figure 11b). The interactions between EVA and PHB in EVA+PHB blends could be ascribed to dipole-dipole interactions between the carbonyl groups of the vinyl acetate in EVA and the carbonyl groups of PHB. Sato et al. [34] proposed the creation of dipole-dipole interactions between carbonyl groups in the crystalline structure of PHB itself and Gao et al. [32] proposed the formation of dipole-dipole interactions between the carbonyl groups in polymers with similar chemical structure such as PVAc, PPC, and PLA. However, the creation of these interactions were discarded because of the similarity in IR and Raman spectra. Furthermore, in EVA/PHB blends, the carbonyl group of the vinyl acetate of EVA will not interact easily with the carbonyl group of PHB, because of the charge withdrawing induced by the methylene group in EVA. Therefore, the improved miscibility and the particular properties of EVA/PHB blends containing less than $50 \mathrm{wt} \%$ PHB can be ascribed to $\mathrm{C}=\mathrm{O} \cdots \mathrm{CH}_{3}$ interactions between vinyl acetate in EVA and PHB.

\subsection{Adhesion properties of EVA/PHB blends}

Tack or initial adhesion is the resistance of an adhesive film to detach from a substrate when low pressure during short time is applied. Therefore, the tack is related to the viscoelastic properties of the adhesive, i.e. the higher is the mobility of the polymer chains, the higher is the tack. Therefore, the existence of physical and interfacial interactions between EVA and PHB phases in EVA+PHB blends may affect their tack.

Figure 12 shows the variation of tack as a function of the temperature for pure EVA, pure PHB and some EVA/PHB blends. Pure PHB does not show tack at any temperature because of its crystallinity and dominant elastic behavior. Pure EVA starts to show tack at $50^{\circ} \mathrm{C}$, temperature at which the rubbery plateau is reached (Figure 7), and the tack increases up to more than $500 \mathrm{kPa}$ at $75-90^{\circ} \mathrm{C}$. EVA/PHB blends containing $60 \mathrm{wt} \%$ or more PHB do not show tack because of the low mobility of the polymeric chains (they show low $\tan \delta$ values - Figure 10) due to the dominance of the stiff PHB phase. Interestingly, all EVA + PHB blends containing $50 \mathrm{wt} \%$ or less PHB show tack and the tack values are even higher than for pure EVA; furthermore, the addition of PHB shifts the maximum value of tack of pure EVA to

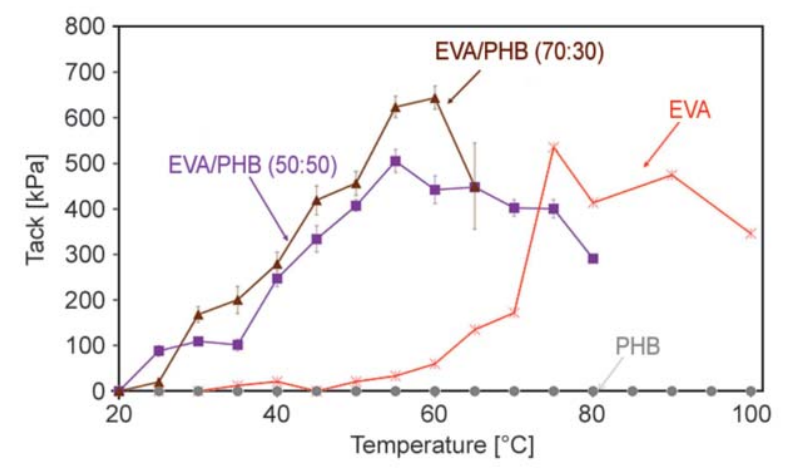

Figure 12. Variation of tack as a function of the temperature for EVA, PHB and some EVA/PHB blends. 
lower temperature, i.e., due to the miscibility and the interfacial interactions between EVA and PHB phases, the mobility of EVA phase in the blends is produced at lower temperature than in pure EVA. EVA/ PHB (80:20) blend shows somewhat similar variation of tack as a function of the temperature than pure EVA confirming that its properties are dominated by EVA phase, in agreement with the similarity in their viscoelastic properties. On the other hand, at temperatures above $60^{\circ} \mathrm{C}$ the tack of all blends decreases because of too high mobility of the polymer chains. As typical example, Figure 13 shows the variation of the tack at $60^{\circ} \mathrm{C}$ of EVA/PHB blends as a function of their PHB content. The tack of the blends increases by increasing their PHB content up to $50 \mathrm{wt} \%$ decreasing suddenly in the blends containing $60 \mathrm{wt} \%$ or more PHB. Interestingly, the tack of EVA/PHB (70:30) blend is the highest because of its particular structure, higher miscibility, more net interfacial interactions, and better thermal and viscoelastic properties with respect to the other blends containing less than $30 \mathrm{wt} \%$ PHB.

Figure $14 \mathrm{a}$ shows the stress-strain curves of pure EVA and different EVA/PHB blends obtained at the

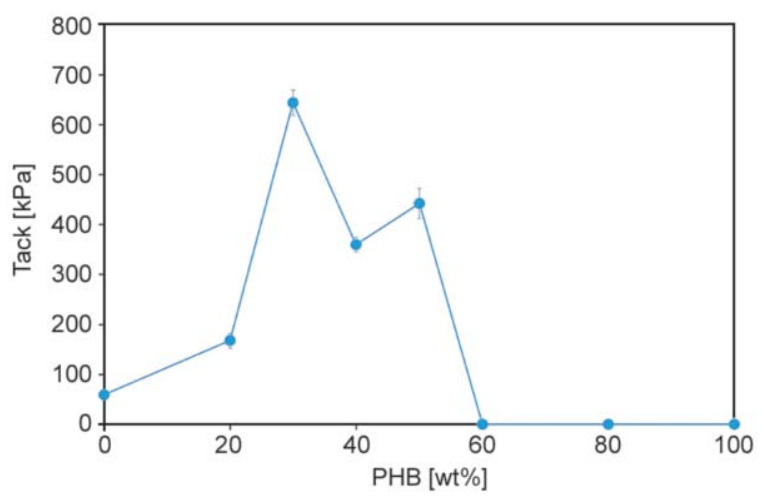

Figure 13. Variation of tack at $60^{\circ} \mathrm{C}$ of EVA/PHB blends as a function of their PHB content.
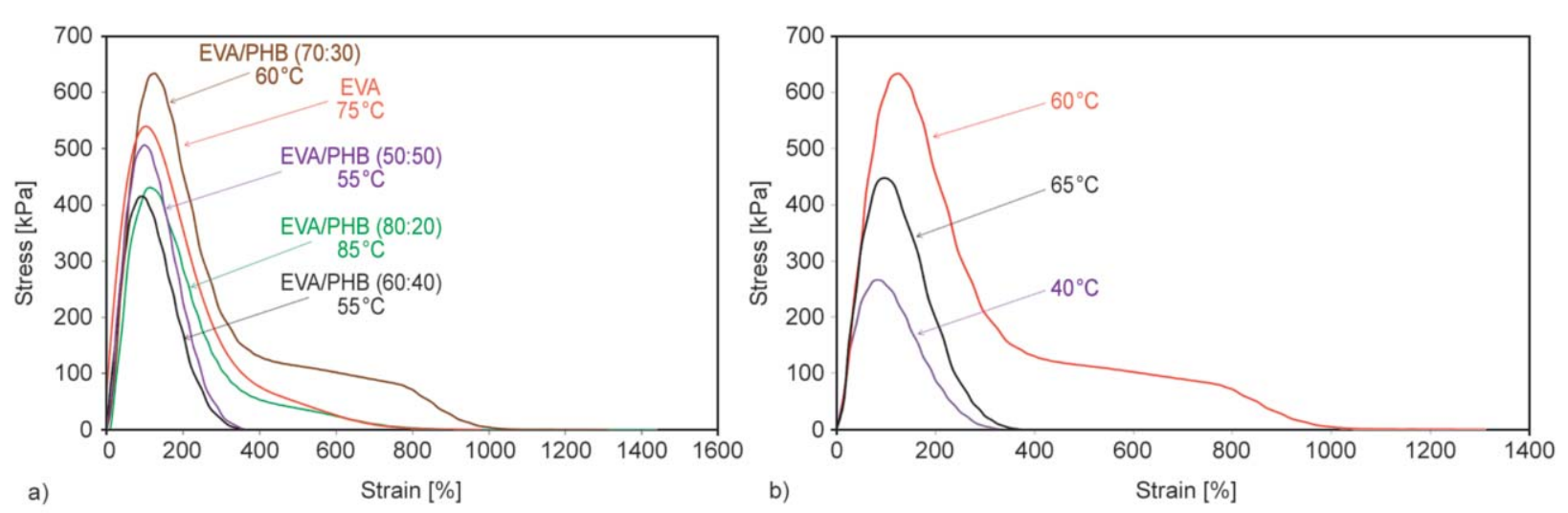

Figure 14. a) Stress-strain curves of EVA and EVA/PHB blends at the temperature of maximum tack. b) Stress-strain curves of EVA/PHB (70:30) blend at different temperatures. temperature at which the maximum tack appears. The stress-strain curves of pure EVA and EVA/PHB blends containing $30 \mathrm{wt} \%$ or less PHB show fibrillation after the maximum stress is reached, i.e., the stress is maintained in a relatively broad range of strain values. Addition of small amounts of PHB enhances the fibrillation of EVA/PHB blend particularly for EVA/PHB (70:30) because of the interactions between the vinyl acetate domains of EVA and PHB phase lead to higher mobility of the ethylene domains. EVA/PHB blends containing 40 and $50 \mathrm{wt} \%$ PHB do not show fibrillation and their tack is lower than for pure EVA, because of low mobility of the polymer chains.

The stress-strain curves of EVA/PHB (70:30) blend at temperatures below, above and in the maximum value of tack $\left(60^{\circ} \mathrm{C}\right)$, are given in Figure $14 \mathrm{~b}$. At temperatures above and below the maximum tack, the stress-strain curves do not show fibrillation and the fibrillation only appears at the temperature where maximum tack is obtained, indicating again that the physical interactions between EVA and PHB phases depend on the temperature, in agreement with previous study made with PLA/PVAc blends [31]. By increasing the temperature, the interactions between EVA and PHB phases become weaker allowing higher mobility of the vinyl acetate domains of EVA (Figure 15). Finally, the final adhesion of pure EVA, pure PHB and EVA/PHB blends was obtained by $180^{\circ}$ peel tests. Figure 16a shows the variation of $180^{\circ}$ peel strength of aluminum 5754/EVA-PHB blend/PET film joints as a function of the PHB content in the blends. $180^{\circ}$ peel strength of the joint made with pure EVA is the highest and decreases by adding PHB, more markedly by increasing the amount of PHB above $60 \mathrm{wt} \%$; because of their stiffness, $180^{\circ}$ peel 


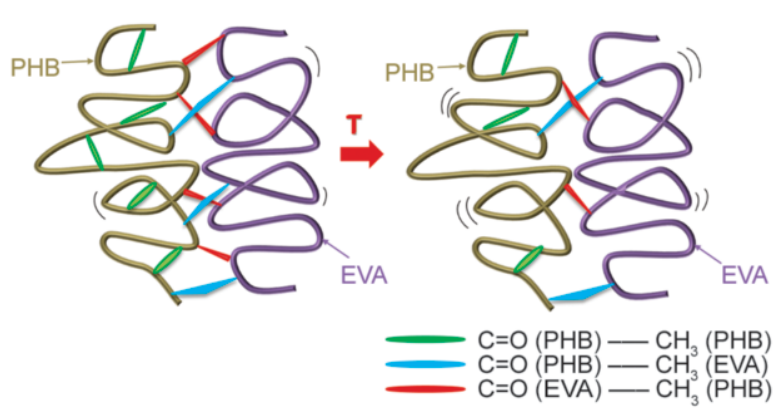

Figure 15. Scheme of the interactions between EVA and PHB polymeric chains in EVA/PHB (70:30) blend by increasing the temperature.

strength values of the joints made with EVA/PHB blends containing more than $70 \mathrm{wt} \%$ PHB are very small. Interestingly, similar $180^{\circ}$ peel strengths are obtained in the joints made with blends containing 20 and $30 \mathrm{wt} \%$ PHB because of the particular structure of EVA/PHB (70:30) that produces higher final adhesion than expected.

The final adhesion was also determined in aluminum 5754/EVA-PHB blend/PP film joints; PP film was used because of its non-polar nature. Figure 16b shows that the highest $180^{\circ}$ peel strengths correspond to the joints made with EVA/PHB blends containing 20 and $30 \mathrm{wt} \%$ PHB, both are higher than for the joint made with pure EVA; in the joints made with EVA/PHB blends containing $40 \mathrm{wt} \%$ or more PHB, a similar trend that the one in Figure 16a is obtained. The enhanced final adhesion of EVA/PHB blends containing 20 and $30 \mathrm{wt} \%$ PHB to PP substrate can be ascribed to the interfacial and physical interactions between the vinyl acetate domains in EVA and the methyl and carbonyl groups in PHB, which facilitate the movement of the ethylene domains in EVA and their interaction with PP substrate surface.

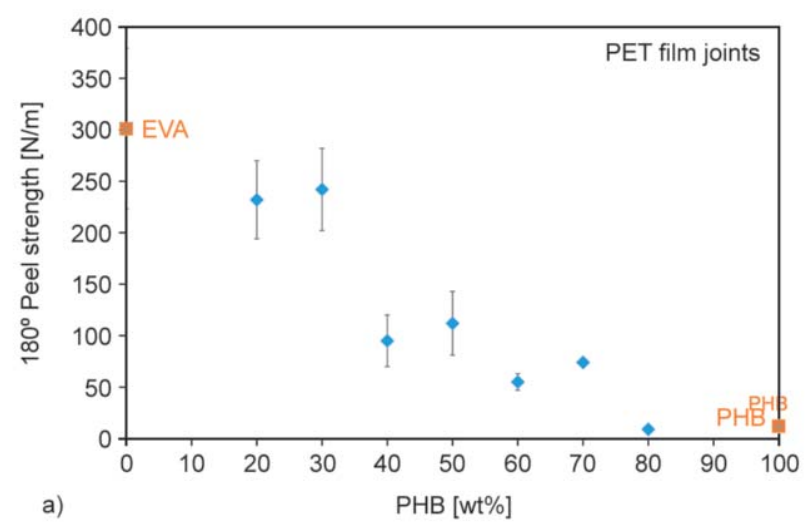

However, in the aluminum 5754/EVA-PHB blend/ PET joints, the interactions between ethylene domains in EVA and PET is not favored because of the polar nature of PET substrate.

\section{Conclusions}

The structure of EVA/PHB blends depended on their PHB content, i.e., PHB phase dominated the structure and the properties of the blends with PHB content higher than $50 \mathrm{wt} \%$, whereas these were determined by EVA phase when PHB content was lower than $50 \mathrm{wt} \%$. However, the structure and properties of EVA/PHB (70:30) blend were different.

Addition of EVA shifted the crystallization and melting of PHB to higher temperatures, irrespective of the amount of PHB in the blends, the variations were less marked in EVA/PHB blends containing less than $40 \mathrm{wt} \%$ PHB due to higher miscibility and the creation of new interfacial interactions between $\mathrm{C}=\mathrm{O}$ and $\mathrm{CH}_{3}$ groups of $\mathrm{PHB}$ and $\mathrm{CH}_{3}$ and $\mathrm{C}=\mathrm{O}$ groups of EVA in the blends. The interactions between EVA and PHB phases led to higher degree of separation of ethylene and vinyl acetate domains in EVA phase in the blends. Addition of small amounts of EVA caused the formation of large PHB spherulites (40$80 \mu \mathrm{m})$, and EVA/PHB (80:20) and EVA/PHB (60:40) blends showed PHB spherulites disseminated in the amorphous EVA matrix. Interestingly, EVA/PHB (70:30) blend showed more amorphous structure. On the other hand, the viscoelastic curves of pure EVA and EVA/PHB blends with 20 and $30 \mathrm{wt} \%$ PHB were similar, but the storage modulus increased suddenly and noticeably in the blends containing $40-50 \mathrm{wt} \%$ PHB due to the crystallization of the immiscible PHB phase.

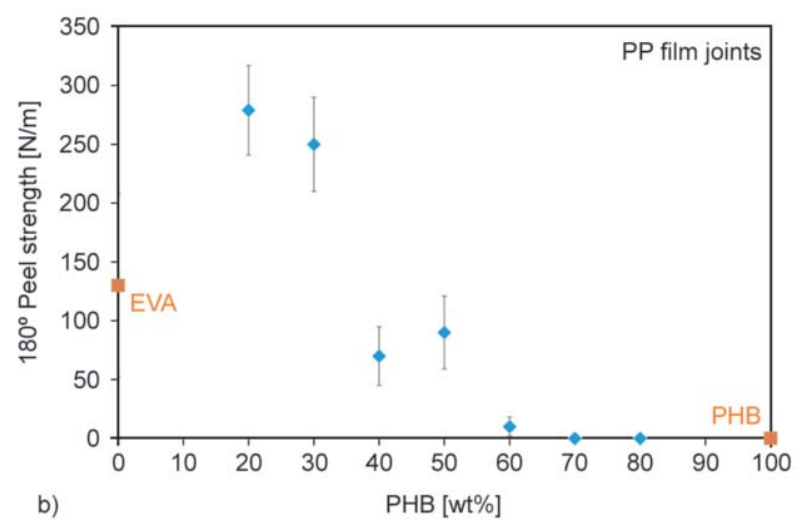

Figure 16. a) Variation of $180^{\circ}$ peel strength of aluminum 5754/EVA-PHB blend/PET film joints as a function of PHB content in the blend. An adhesion failure to PET substrate was always obtained. b) Variation of $180^{\circ}$ peel strength of aluminum 5754/EVA-PHB blend/PP film joints as a function of PHB content in the blend. An adhesion failure to PP film was always obtained. 
EVA/PHB blends containing $60 \mathrm{wt} \%$ or more PHB did not show tack because of the low mobility of the polymeric chains but high tack, even higher than for pure EVA, was obtained in the blends containing less than $50 \mathrm{wt} \%$ PHB. The tack of EVA/PHB (70:30) blend was the highest because of its particular crystallinity, structure and interactions between EVA and PHB phases. Finally, the final adhesion of aluminum 5754/EVA-PHB blend/PP film joints was higher in the joints made with EVA/PHB blends containing 20-30 wt \% PHB than for pure EVA because of the favored interfacial interactions between the ethylene domains in EVA phase and PP substrate surface.

\section{Acknowledgements}

Authors thanks Dirección de Tecnología de Repsol S.A and Repsol Química (Madrid, Spain) for supplying EVA and PHB materials.

\section{References}

[1] Bugnicourt E., Cinelli P., Lazzeri A., Alvarez V.: Polyhydroxyalkanoate (PHA): Review of synthesis, characteristics, processing and potential applications in packaging. Express Polymer Letters, 8, 791-808 (2014). https://doi.org/10.3144/expresspolymlett.2014.82

[2] Babu R. P., O’Connor K., Seeram R.: Current progress on bio-based polymers and their future trends. Progress in Biomaterials, 2, 1-16 (2013).

https://doi.org/10.1186/2194-0517-2-8

[3] Steinbüchel A., Valentin H. E.: Diversity of bacterial polyhydroxyalkanoic acids. FEMS Microbioly Letters, 128, 219-228 (1995). https://doi.org/10.1016/0378-1097(95)00125-O

[4] Lenz R. W.: Biodegradable polymers. in 'Biopolymers I. Advances in Polymer Science' (eds.: Langer R. S., Peppas N. A.) Springer, Berlin, 1-40 (1993).

[5] Dawes E. A., Senior P. J.: The role and regulation of energy reserve polymers in micro-organisms. Advances in Microbial Physiology, 10, 135-266 (1973).

https://doi.org/10.1016/S0065-2911(08)60088-0

[6] Chia K-H., Ooi T-F., Saika A., Tsuge T., Sudesh K.: Biosynthesis and characterization of novel polyhydroxyalkanoate polymers with high elastic property by Cupriavidus necator PHB-4 transformant. Polymer Degradation and Stability, 95, 2226-2232 (2010). https://doi.org/10.1016/j.polymdegradstab.2010.09.011

[7] Xu J., Guo B-H., Yang R., Wu Q., Chen G-Q., Zhang Z. M.: In situ FTIR study on melting and crystallization of polyhydroxyalkanoates. Polymer, 43, 6893-6899 (2002).

https://doi.org/10.1016/S0032-3861(02)00615-8
[8] Khanna S., Srivastava A. K.: Recent advances in microbial polyhydroxyalkanoates. Process Biochemistry, 40, 607-619 (2005).

https://doi.org/10.1016/j.procbio.2004.01.053

[9] Belgacem M. N., Gandini A.: Materials from vegetable oils: Major sources, properties and applications. in 'Monomers, polymers and composites from renewable resources' (eds.: Belgacem M. N., Gandini A.) Elsevier, Amsterdam, 39-66 (2008).

https://doi.org/10.1016/B978-0-08-045316-3.00003-X

[10] Inoue Y., Kamiya J., Yamamoto Y., Chujo R., Doi Y.: The microstructures of commercially available poly(3hydroxybutyrate-co-3-hydroxyvalerate)s. Macromolecules, 22, 3800-3802 (1989).

https://doi.org/10.1021/ma00199a051

[11] Shimamura E., Kasuya K., Kobayashi G., Shiotani T., Shima Y., Doi Y.: Physical properties and biodegradability of microbial poly(3-hydroxybutyrate-co-3-hydroxyhexanoate). Macromolecules, 27, 878-880 (1994). https://doi.org/10.1021/ma00081a041

[12] Avella M., Martuscelli E.: Poly-D-(-)(3-hydroxybutyrate)/poly(ethylene oxide) blends: Phase diagram, thermal and crystallization behaviour. Polymer, 29, 1731-1737 (1988).

https://doi.org/10.1016/0032-3861(88)90384-9

[13] Paglia E. D., Behrame P. L., Canetti M., Seves A., Martcandalli B., Martuscelli E.: Crystallization and thermal behaviour of poly $(\mathrm{D}(-)$ 3-hydroxybutyrate)/poly(epichlorohydrin) blends. Polymer, 34, 996-1001 (1993). https://doi.org/10.1016/0032-3861(93)90220-5

[14] Greco P., Martuscelli E.: Crystallization and thermal behaviour of poly(D(-)-3-hydroxybutyrate)-based blends. Polymer, 30, 1475-1483 (1989).

https://doi.org/10.1016/0032-3861(89)90219-X

[15] Marand H., Collins M.: Crystallization and morphology of poly(vinylidene fluoride)/poly(3-hydroxybutyrate) blends. Polymer Preprints, 31, 552-553 (1990).

[16] Blümm E., Owen A. J.: Miscibility, crystallization and melting of poly(3-hydroxybutyrate)/ poly(L-lactide) blends. Polymer, 36, 4077-4081 (1995).

https://doi.org/10.1016/0032-3861(95)90987-D

[17] Abbate M., Martuscelli E., Ragosta G., Scarinzi G.: Tensile properties and impact behaviour of poly(D(-)3hydroxybutyrate)/rubber blends. Journal of Materials Science, 26, 1119-1125 (1991). https://doi.org/10.1007/BF00576797

[18] Ma P., Cai X., Chen M., Dong W., Lemstra P. J.: Partially bio-based thermoplastic elastomers by physical blending of poly(hydroxyalkanoate)s and poly(ethylene-co-vinyl acetate). Express Polymer Letters, 8, 517527 (2014).

https://doi.org/10.3144/expresspolymlett.2014.55

[19] Schaible S., Bernet C., Ledergeber P., Balmer T., Brändli C.: Basic study on the evaluation of thermoplastic polymers as hot-melt adhesives for mixed-substrate joining. Journal of Applied Sciences, 6, 579-592 (2016). https://doi.org/10.4236/ojapps.2016.68057 
[20] Babu G. N., Hammar W. J., Rutherford D. R., Lenz R. W., Richards R., Goodwin S. D.: Poly-3-hydroxyalkanoates as pressure sensitive adhesives. in 'Proceeding of 1996 International Symposium on Bacterial Polyhydroxyalkanoates. Davos, Switzerland' 48-55 (1996).

[21] Gassner F., Owen A. J.: On the physical properties of BIOPOL/ethylene-vinyl acetate blends. Polymer, 33, 2508-2512 (1992).

https://doi.org/10.1016/0032-3861(92)91131-K

[22] Yoon J-S., Oh S-H., Kim M-N.: Compatibility of poly (3-hydroxybutyrate)/poly(ethylene-co-vinyl acetate) blends. Polymer, 39, 2479-2487 (1998).

https://doi.org/10.1016/S0032-3861(97)00556-9

[23] El-Taweel S. H., Stoll B., Schick C.: Crystallization kinetics and miscibility of blends of polyhydroxybutyrate (PHB) with ethylene vinyl acetate copolymers (EVA). e-Polymers, 11, 191-206 (2011).

https://doi.org/10.1515/epoly.2011.11.1.191

[24] Barham P. J., Keller A., Otun E. L., Holmes P. A.: Crystallization and morphology of a bacterial thermoplastic: Poly-3-hydroxybutyrate. Journal of Materials Science, 19, 2781-2794 (1984).

https://doi.org/10.1007/BF01026954

[25] Corre Y-M., Bruzaud S., Audic J-L., Grohens Y.: Morphology and functional properties of commercial polyhydroxyalkanoates: A comprehensive and comparative study. Polymer Testing, 31, 226-235 (2012).

https://doi.org/10.1016/j.polymertesting.2011.11.002

[26] Yoon J-S., Oh S-H., Kim M-N., Chin I-J., Kim Y-H.: Thermal and mechanical properties of poly(L-lactic acid)-poly(ethylene-co-vinyl acetate) blends. Polymer, 40, 2303-2312 (1999).

https://doi.org/10.1016/S0032-3861(98)00463-7

[27] Lopes J. R., dos Reis R. A., Almeida L. E.: Production and characterization of films containing poly(hydroxybutyrate) (PHB) blended with esterified alginate (ALG-e) and poly(ethylene glycol) (PEG). Journal of Applied Polymer Science, 134, 44362/1-44362/10 (2016).

https://doi.org/10.1002/app.44362

[28] Mottin A. C., Ayres E., Oréfice R. L., Câmara J. J. D.: What changes in poly(3-hydroxybutyrate) (PHB) when processed as electrospun nanofibers or thermo-compression molded film? Materials Research, 19, 57-66 (2016).

https://doi.org/10.1590/1980-5373-MR-2015-0280

[29] El-Hadi A. M.: The effect of additives interaction on the miscibility and crystal structure of two immiscible biodegradable polymers. Polímeros, 24, 9-16 (2014). https://doi.org/10.4322/polimeros.2014.039

[30] Zhang J., Sato H., Tsuji H., Noda I., Ozaki Y.: Differences in the $\mathrm{CH}_{3} \cdots \mathrm{OC}$ interactions among poly(L-lactide), poly(L-lactide)/poly(D-lactide) stereocomplex, and poly(3-hydroxybutyrate) studied by infrared spectroscopy. Journal of Molecular Structure, 735-736, 249-257 (2005).

https://doi.org/10.1016/j.molstruc.2004.11.033
[31] Furukawa T., Sato H., Murakami R., Zhang J., Duan YX., Noda I., Ochiai S., Ozaki Y.: Structure, dispersibility, and crystallinity of poly(hydroxybutyrate)/poly(Llactic acid) blends studied by FT-IR microspectroscopy and differential scanning calorimetry. Macromolecules, 38, 6445-6454 (2005).

https://doi.org/10.1021/ma0504668

[32] Gao J., Bai H., Zhang Q., Gao Y., Chen L., Fu Q.: Effect of homopolymer poly(vinyl acetate) on compatibility and mechanical properties of poly(propylene carbonate)/poly(lactic acid) blends. Express Polymer Letters, 6, 860-870 (2012).

https://doi.org/10.3144/expresspolymlett.2012.92

[33] Porter M. M., Yu J.: Crystallization kinetics of poly(3hydroxybutyrate) granules in different environmental conditions. Journal of Biomaterials and Nanobiotechnology, 2, 301-310 (2011).

https://doi.org/10.4236/jbnb.2011.23037

[34] Sato H., Murakami R., Padermshoke A., Hirose F., Senda K., Noda I., Ozaki Y.: Infrared spectroscopy studies of $\mathrm{CH} \cdots \mathrm{O}$ hydrogen bondings and thermal behavior of biodegradable poly(hydroxyalkanoate). Macromolecules, 37, 7203-7213 (2004).

https://doi.org/10.1021/ma049117o

[35] Zhang J., Sato H., Noda I., Ozaki Y.: Conformation rearrangement and molecular dynamics of poly(3-hydroxybutyrate) during the melt-crystallization process investigated by infrared and two-dimensional infrared correlation spectroscopy. Macromolecules, 38, 42744281 (2005).

https://doi.org/10.1021/ma0501343

[36] Zhang M., Thomas N. L.: Blending polylactic acid with polyhydroxybutyrate: The effect on thermal, mechani$\mathrm{cal}$, and biodegradation properties. Advances in Polymer Technology, 30, 67-79 (2011).

https://doi.org/10.1002/adv.20235

[37] Sharhan O., Yahaya A. H., Mohammed F. A. Q.: Crystallization and thermal behaviour of poly(3-hydroxybutyric acid)/poly(vinyl acetate) blend films. Asian Journal of Chemistry, 28, 607-612 (2016).

https://doi.org/10.14233/ajchem.2016.19429

[38] Ren H., Zhang Y., Zhai H., Chen J.: Production and evaluation of biodegradable composites based on polyhydroxybutyrate and polylactic acid reinforced with short and long pulp fibers. Cellulose Chemistry and Technology, 49, 641-652 (2015).

[39] Choi H. J., Park S. H., Yoon J. S., Lee H-S., Choi S. J.: Rheological study on poly-D(-) (3-hydroxybutyrate) and its blends with poly(ethylene oxide). Polymer Engineering and Science, 35, 1636-1642 (1995). https://doi.org/10.1002/pen.760352010

[40] Chen L. J., Wang M.: Production and evaluation of biodegradable composites based on PHB-PHV copolymer. Biomaterials, 23, 2631-2639 (2002). https://doi.org/10.1016/S0142-9612(01)00394-5 